\title{
Regionalization and Spatiotemporal Variation of Drought in China Based on Standardized Precipitation Evapotranspiration Index (1961-2013)
}

\author{
Xiongfei Liu, ${ }^{1,2}$ Shixin Wang, ${ }^{1}$ Yi Zhou, ${ }^{1}$ Futao Wang, ${ }^{1}$ Wenjun Li, ${ }^{1,2}$ and Wenliang Liu ${ }^{1}$ \\ ${ }^{1}$ Institute of Remote Sensing and Digital Earth, Chinese Academy of Sciences, Beijing 100101, China \\ ${ }^{2}$ University of Chinese Academy of Sciences, Beijing 100049, China \\ Correspondence should be addressed to Yi Zhou; zhouyi@radi.ac.cn
}

Received 30 January 2015; Revised 12 May 2015; Accepted 18 May 2015

Academic Editor: S. Vicente-Serrano

Copyright ( 2015 Xiongfei Liu et al. This is an open access article distributed under the Creative Commons Attribution License, which permits unrestricted use, distribution, and reproduction in any medium, provided the original work is properly cited.

\begin{abstract}
China is considered to be one of the most drought prone countries. This study is dedicated to analyzing the regionalization and spatiotemporal variations of drought based on the Standardized Precipitation Evapotranspiration Index, which covers the period 1961-2013 across 810 stations in China. Using Spatial “K”luster Analysis by Tree Edge Removal method, China was divided into eight regions: southwest (SW), northeast (NE), north (N), southeast (SE), Yangtze River (YR), northwest (NW), central China (C), and Tibet Plateau (TP). The spatiotemporal variations of drought characteristics indicated that the drought count in NE and $\mathrm{C}$ was generally high. Southern China and NW had suffered long drought duration and extreme severity. The MK test results show that stations with significant drying trends mainly locate in SW, N, NW, and C. The severe drought frequency was very high in 1990 s and 2000s. Furthermore, more attention should be paid to abnormal less precipitation in summer and abnormal high temperature in spring in SW, NE, N, and C. Besides, abnormal less precipitation is the main factor of drought in SE and YR in whole year. This study is anticipated to support the water resources management, and to promote the realization of environmental protection and agricultural production.
\end{abstract}

\section{Introduction}

A drought is an extended period conquered by dry weather that produces a serious water supply deficiency. With the characteristics of high frequency, wide distribution, and long duration, drought ranks first among all natural hazards. It would cause enormous socioeconomic damage and pose grave threats to the environment, agriculture, health, and ecosystem. The adverse influence would continue for a long time after the drought end. As a result of frequent abnormal low precipitation and abnormal high temperature since the twentieth century, drought events show a growth trend [1].

For the monsoon climate condition and natural geographical environment, China has suffered numerous extreme droughts in the past 50 years. The drought affected area accounts for $60 \%$ of all hazard-affected area. The average affected crops area (loses more than 30\%) is 9.5 million hectares per year, accounting for $6.7 \%$ of total sown area. On average, $70-80$ billion $\mathrm{kg}$ of food, accounting for $17 \%$ of total yield, would be lost per year [2, 3]. From the autumn of 2009 to the spring of 2010, southwest China suffered an extreme drought, owing to abnormal low precipitation and abnormal high temperature [4]. Over 16 million people and 11 million livestock were subjected to water shortage. Meanwhile, about $25 \%$ farmland had no harvest. Drought is affecting social and economic development of China significantly. Thus, it is important to carry on more researches for drought prevention and management in China.

The government and public have paid great attention to the conundrum of when and where overwhelming drought events would happen. However, the complex spatiotemporal characteristics of drought hamper work on drought assessment. Many researchers are concentrating on this research direction $[5,6]$. Vicente-Serrano identified several subregions 
using Principal Component Analysis (PCA) and hierarchical cluster method in Iberian Peninsula based on 51 Standardized Precipitation Index (SPI) series and analyzed the different characteristics of these regions $[7,8]$. Logan pointed out that the SPI showed a slow growth in the eastern parts of the Kansas River Basin. He pointed out that if temperatures increase, an increase in precipitation may still result in a decrease in moisture availability [9]. Gocic identified three subregions in Serbia using SPI and S-Mode PCA and analyzed drought frequency in these regions, respectively [10]. Numerous researchers have studied drought characteristics in China [11-14]. Depending on climate characteristics, scholars divided China into $8,10,11$, and 13 regions $[13,15-$ 19]. Zhai analyzed the changing trend of precipitation and temperature, which covers the period 1951-2003 across 606 stations $[20,21]$, and pointed out that less precipitation is the principal factor of drought. He also pointed out that there is a negative, inapparent correlation between temperature and PDSI. Li et al. divided southeast China into five subregions and found Yunnan is frequently struck by severe and extreme droughts among these regions [22]. Zhang et al. found that Pearl River Basin tends to be dryer in rainy season and wetter in winter [23]. Wang et al. highlighted that drought hazard in Shandong province is becoming more and more acute owing to abnormal high temperature and local precipitation decreasing [24]. Yu et al. investigated the variation of annual SPEI changing trend, drought percentage area, drought longest duration, and drought frequency. He explored significant drying trends that occurred over northern China, southwest part of northeast China, central and east of northwest China, and central and southwest part of southwest China [14]. These previous studies concentrated on the regionalization and spatiotemporal variation of drought in China. Yet the methods used for drought regionalization are usually based on EOF or hierarchical cluster analysis instead of geographic methods, and few analyses discussed the variation of drought characteristics. Therefore, it is necessary to get the regionalization using geographic methods and analyze the drought characteristics of all regions.

Due to diverse causations of drought, such as precipitation, temperature, wind, vegetation and soil, it is still a big challenge to monitor and evaluate drought accurately. A number of different indices, such as Palmer Drought Severity Index (PDSI) [25], Standardized Precipitation Index (SPI) [26], Compound Index (CI) [27], Self-Calibrating PDSI (SCPDSI) [28], and Standardized Precipitation Evapotranspiration Index (SPEI) [29], have been proposed to quantify drought. Vicente-Serrano et al. carried out Standardized Precipitation Evapotranspiration Index (SPEI), in 2010, and founded a new global 0.5 gridded dataset (1901-2013) [30]. SPEI combines the sensitivity to changes in temperature with the simplicity of calculation and the multitemporal nature. Many authors used SPEI to detect drought over globe or regions and found it is particularly suited to detect, monitor, and explore the consequences of drought conditions [31, 32].

This work will address the drought regionalization and spatiotemporal variation of drought characteristics based on SPEI across China. The main objectives of this study are (1) to get drought regionalization in China using Spatial "K"luster
Analysis by Tree Edge Removal method, (2) to analyze the spatiotemporal variation of drought characteristics over identification regions, and (3) to analyze how abnormal precipitation and abnormal temperature affect SPEI in different months in eight region.

\section{Study Area and Data}

Because of vast landmass with complicated atmospheric circulation patterns and undulating terrain, precipitation and temperature in China are highly uneven in space and time. Based on statistic from 1961 to 2013, average annual precipitation varies from $15 \mathrm{~mm}$ to over $2700 \mathrm{~mm}$ per year, decreasing from southeast to northwest. Annual mean temperature varies from $-12^{\circ} \mathrm{C}$ to $25^{\circ} \mathrm{C}$ and gradually decreases from south to north. Eastern China is affected by the East Asian Summer Monsoon and primarily dominated by humid and semihumid climate. Precipitation is asymmetrical in seasonal distribution and mainly come with the monsoon in summer. The western China, mainly dominated by arid and semiarid climate, has the lowest annual rainfall of around $200 \mathrm{~mm}$.

The meteorological data, including China surface climate daily dataset (V3.0) and China surface climate monthly dataset (V3.0), was collected from China Meteorological Data Sharing Service System (http://cdc.nmic.cn/home.do). Datasets' quality, continuity, and homogeneity have been checked by China Metrological Administration [33]. The daily dataset contains 839 stations, while monthly dataset only includes 756 stations. In order to get more sites, these two datasets were combined to a new monthly dataset. The data records covering the period from 1961 to 2013 were used, because most stations have not been built before 1961. The longer the data series, the more robust the SPEI calculated. So 29 stations with missing data longer than 120 months (10 years) were removed. This would guarantee that the data length of 810 selected stations is longer than or equal to 43 years (Figure 1). In order to compute SPEI index, Ordinary Kriging method was utilized to interpolate the few missing data [34]. Taiwan province is not included in this study for the necessary data were not available. It should also be noted that the regionalization and spatiotemporal characteristics might be inaccurate in western Tibet for the shortage of data.

\section{Methodology}

3.1. Standardized Precipitation Evapotranspiration Index. Standardized Precipitation Evapotranspiration Index (SPEI), carried out by Vicente-Serrano et al. in 2010 [29], is a multiscales drought index based on climatic data. It can describe water deficit effectively with multiple time scales, reflecting the lag relation between different water resources, precipitation, and evapotranspiration. Three-month SPEI was employed in this study to characterize short duration droughts [35]. More details about SPEI can be obtained in its website (http://sac.csic.es/spei/index.html) and previous papers [29, 36]. The SPEI software can be downloaded from internet freely (http://digital.csic.es/handle/10261/10002). 


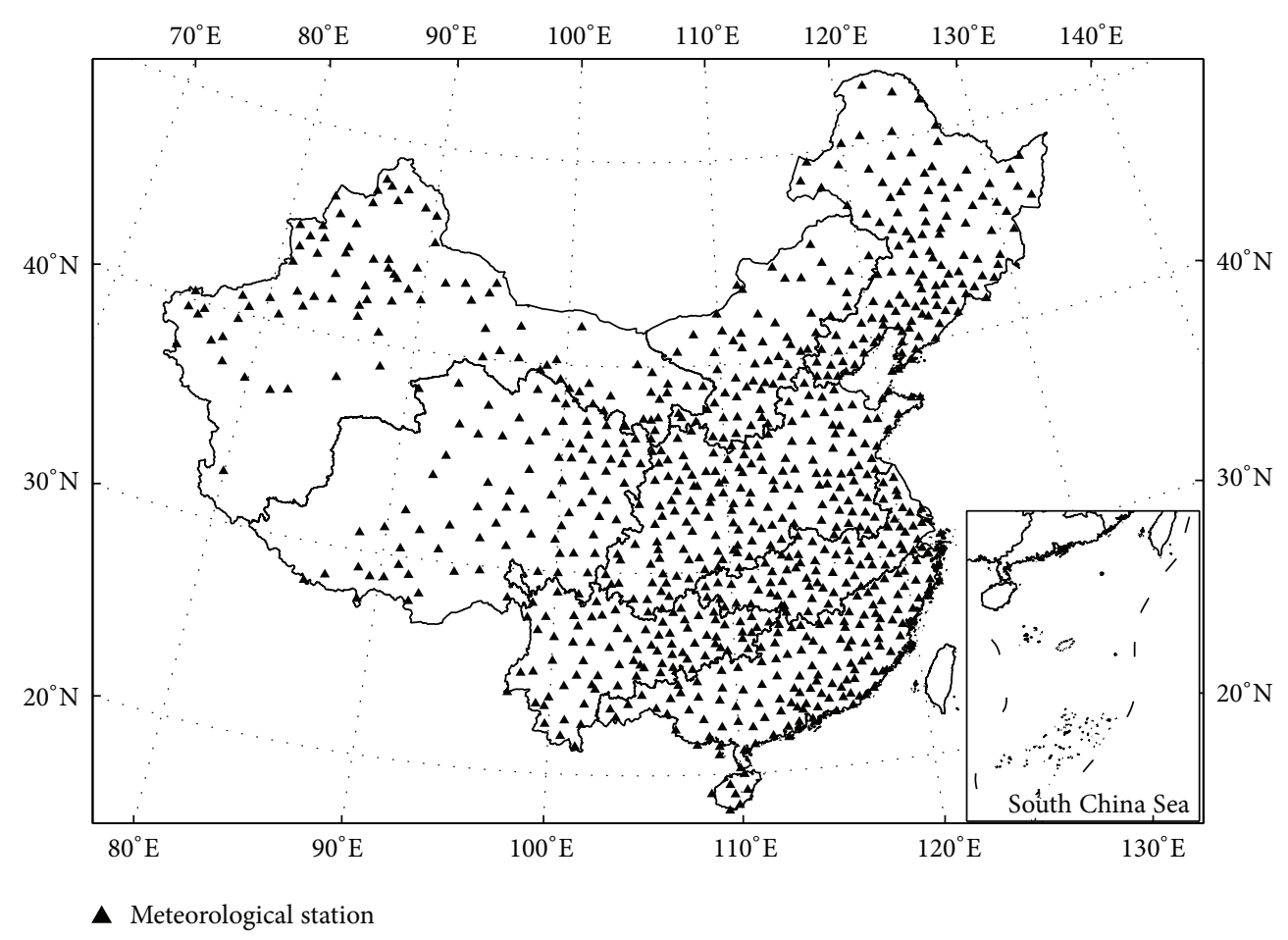

FIGURE 1: Geographic location of China and meteorological stations.

TABLE 1: Categorization of dryness grade by the SPEI.

\begin{tabular}{lcc}
\hline SPEI & Categories & Frequency (\%) \\
\hline $2.0 \leq$ SPEI & Extreme wetness & 2.2 \\
$1.5 \leq$ SPEI $<2.0$ & Severe wetness & 4.4 \\
$1.0 \leq$ SPEI $<1.5$ & Moderate wetness & 9.2 \\
$0.5 \leq \mathrm{SPEI}<1.0$ & Slight wetness & 15.0 \\
$-0.5<\mathrm{SPEI}<0.5$ & Normal & 38.4 \\
$-1.0<\mathrm{SPEI} \leq-0.5$ & Slight dryness & 15.0 \\
$-1.5<\mathrm{SPEI} \leq-1.0$ & Moderate dryness & 9.2 \\
$-2.0<\mathrm{SPEI} \leq-1.5$ & Severe dryness & 4.4 \\
$\mathrm{SPEI} \leq-2.0$ & Extreme dryness & 2.2 \\
\hline
\end{tabular}

SPEI is a normalized index so that the mean SPEI is 0 , and the standard deviation is 1 for the location and desired period. SPEI value was divided with 0.5 steps in this study. The meteorological condition can be classified into nine categories based on SPEI according to Table 1.

3.2. Spatial "K"luster Analysis by Tree Edge Removal. It is quite natural for us to organize, group, differentiate, and catalog our data to help us make better sense of it. It will help us make better comprehension of the regional characteristics of drought by grouping hundreds of meteorological stations into few clusters that are internally similar in time and contiguous in space. So far, there are already many partitioning algorithms that can be used to get the drought regionalization, such as Empirical Orthogonal Function (EOF),
K-means cluster analysis, and hierarchical cluster analysis $[37,38]$. EOF is widely used in the meteorological field. This multivariate technique can reduce the dimensionality of dataset by computing a set of new orthogonal variables with the decreasing order of importance. The S-Mode can be implemented to identify the spatial patterns of drought. However, EOF cannot get the partition directly. Researchers have to get the clusters artificially according to EOF results. The goal of the K-means algorithm and hierarchical cluster method is to make the differences between data in a group, over all group, minimum. Both two methods do not consider the spatial characteristics, so points in the same region may be not adjacent. Both methods are not suited to get geographical regionalization.

In order to achieve better cluster result, the geographical location and nonspatial feature of meteorological stations should both be constrained. So far, various methods can regionalize spatial objects $[39,40]$. The already published method, Spatial "K"luster Analysis by Tree Edge Removal (SKATER), is an efficient method for regionalization of socioeconomic unites represented as spatial objects, which combines the use of a Minimum Spanning Tree with combinational optimization techniques [41]. SKATER can summarize both data spatial relationships and nonspatial feature similarity and group spatial objects into homogeneous contiguous regions in a short time with good quality, especially when applied to large datasets. The algorithm also allows restrictions to be included in the regionalization procedure. It is a good choice for drought regionalization. 


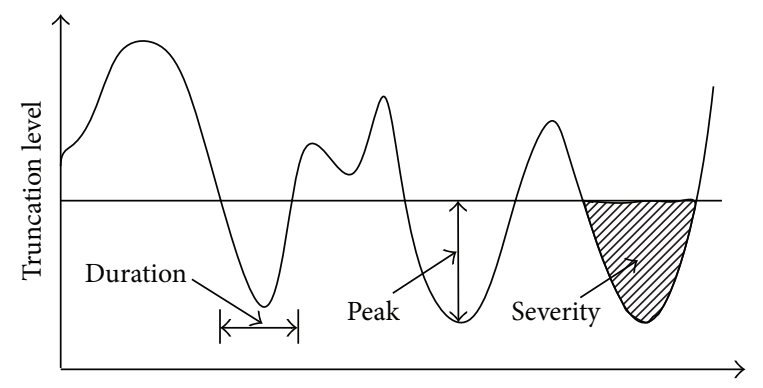

FIGURE 2: Run theory and drought characteristics.

The process of this method is as follows:

(a) Create a connective graph that captures the neighborhood relationship between spatial objects using Delaunay Triangulation method.

(b) Compute the weight of each edge in the graph according to the similarity between the property information.

(c) Simplify the connective graph into a connected tree without circuits, namely, Minimum Spanning Tree.

(d) Divide the Minimum Spanning Tree into several subtrees by removal of several edges that link dissimilar clusters.

(e) Merge all counties into one region if their nearest station is in the same subtree.

3.3. Run Theory. Currently, the most frequently used method to identify drought event is run theory [42]. It can easily recognize drought properties, which are very useful for drought characterization. A drought event is a process when SPEI is less than the truncation level ( -0.5 in this study). As derived from Figure 2, a drought event consists of the following major components: duration, severity, and peak. Drought events with peak less than -1.5 are severe drought events. Drought count for one site means the sum of all drought events that are extracted by run theory. Consider the following:

(a) Duration: it is the total months that a drought event lasts. In other words, it is the period between the onset and termination.

(b) Severity: it indicates a cumulative deficiency of SPEI during a drought event.

(c) Peak: it is the minimal SPEI during a drought event.

3.4. Mann-Kendall Test. Trends of drought characteristics were tested using Mann-Kendall test. Mann-Kendall is a nonparametric statistical test method and is suitable for detecting nonlinear tendencies of nonnormal distribution variables $[43,44]$. So it has been extensively used in long-term tendency of meteorological series. Assuming the random and independent time series is $x_{1}, x_{2}, \ldots, x_{n}$, then the statistical parameter $S$ can be calculated as follows:

$$
S=\sum_{j=1}^{n-1} \sum_{k=j+1}^{n} \operatorname{sgn}\left(x_{k}-x_{j}\right)
$$

where $\operatorname{sgn}\left(x_{k}-x_{j}\right)=\left\{\begin{array}{cc}1 & x_{k}-x_{j}>0 \\ 0 & x_{k}-x_{j}=0 \\ -1 & x_{k}-x_{j}<0\end{array}\right.$ and $n$ is the sample amount. Then normalized test statistic is computed as follows:

$$
Z= \begin{cases}\frac{S-1}{\sqrt{\operatorname{Var}(S)},} & S>0, \\ 0, & S=0, \\ \frac{S+1}{\sqrt{\operatorname{Var}(S)}}, & S<0 .\end{cases}
$$

$Z$ follows the standard normal distribution and can indicate whether the trend is significant. In this study, the tendency of drought duration, severity, and peak was classified according to critical values of $Z$. $Z$ values equal to $1.645(\alpha<0.1), 1.96(\alpha<0.05), 2.58(\alpha<0.01)$, and 3.29 $(\alpha<0.001)$ are associated with 90\%, 95\%, 99\%, and $99.9 \%$ confidence intervals, respectively. Much more details can be found in previous study [45].

\section{Results and Discussion}

4.1. Drought Regionalization of China. China has a vast country with complicated terrain and various climates. It is necessary to divide China into several homogeneous regions to facilitate subsequent analysis. In this study, the homogeneous regions were identified using SKATER in terms of the 810 SPEI series. The result obtained by Process $C$ is a collection of points and lines. The points connected by lines have much more similar characteristics. Based on this result, drought regionalization can be obtained in different scales easily.

In China, the smallest unit of drought prevention and management is county. However, not all counties have a meteorological station. Therefore, it is necessary to get drought regionalization based on county. After Process E, all counties were merged into one region if their nearest meteorological station is in the same cluster. At last, China was divided into eight parts: southwest (SW), northeast (NE), north $(\mathrm{N})$, southeast (SE), Yangtze River (YR), northwest (NW), central China (C), and Tibet Plateau (TP) (Figure 3). The statistical information of these regions is shown in Table 2. The area of NW and TP is much larger than other regions; meanwhile the area of YR is smallest, only covering $4.5 \%$ of China mainland. NW is an arid region, and the replenishment of water resources in this region is mainly from melting glacial and perennial frozen soil, not from precipitation. SE, SW, and YR are humid regions. NE, N, C, and TP are transition regions (subhumid and semiarid region).

4.2. Spatial Distribution of Drought Characteristics. Drought events in all stations were identified by run theory. Drought 

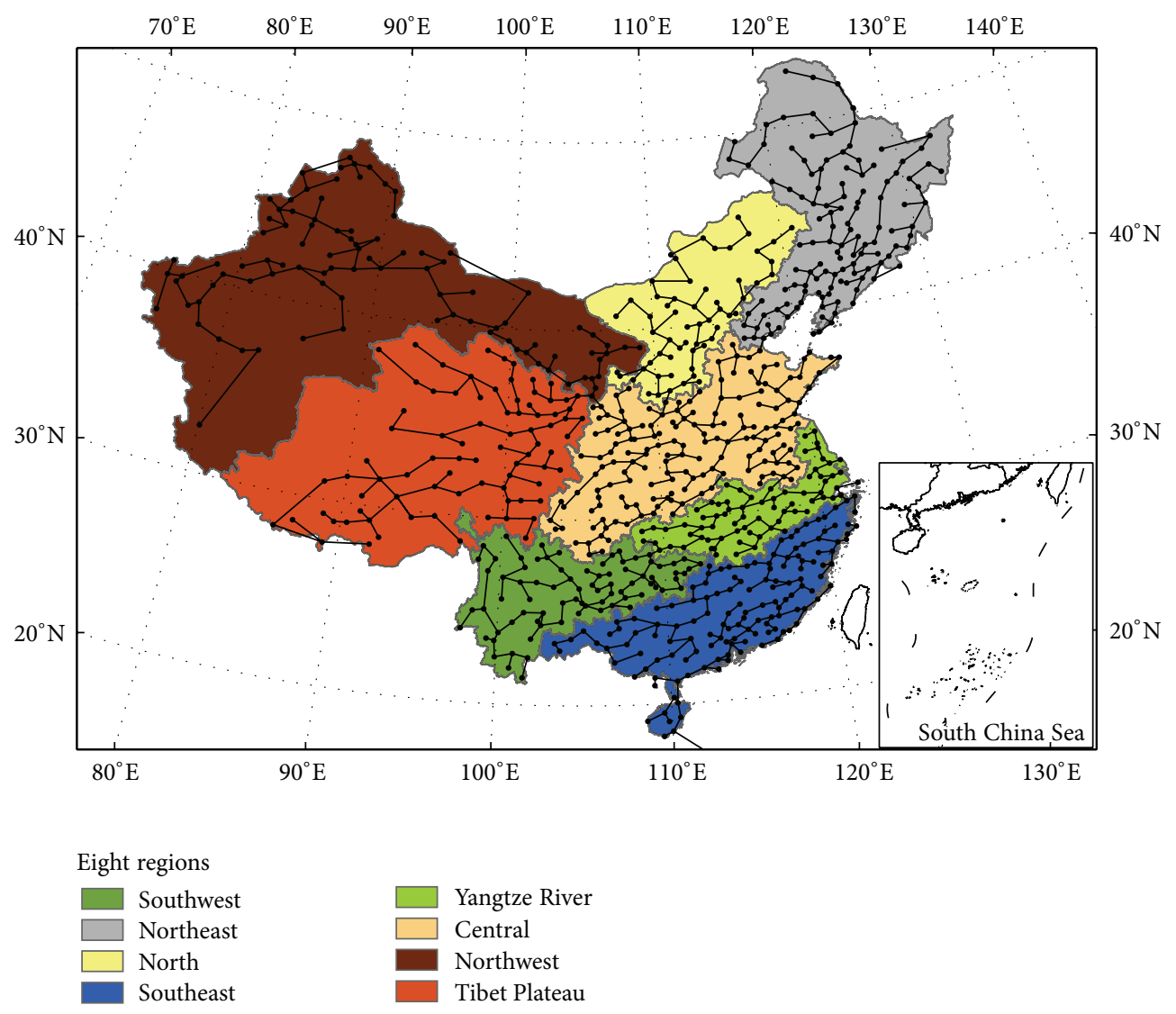

FIgURE 3: Locations of eight regions within China.

TABLE 2: Statistical information of eight regions.

\begin{tabular}{lcccccccc}
\hline Region & SW & NE & N & SE & YR & NW & C & TP \\
\hline Station amount & 80 & 123 & 58 & 140 & 74 & 160 & 94 & 81 \\
Coverage area (\%) & 7.2 & 12.9 & 7.9 & 8.9 & 4.5 & 25.8 & 12.2 & 20.6 \\
\hline
\end{tabular}

characteristics of all drought events, including duration, severity, and peak, have been recorded. For all stations in China from 1961 to 2013, 64448 drought records were extracted. 25421 records' duration is longer than or equal to 3 months; 21612 records' severity is smaller than $-3 ; 17564$ records' peak is smaller than -1.5 . On average, there are about 80 drought events for each station, with 2.6 months drought duration, -2.8 drought severity, and -1.22 drought peak. It is needed to point out that drought events were extracted based on points rather than surface, and it would have great change based on other time scales SPEI series.

Spatial distribution of drought count, mean duration, and mean severity were shown in Figure 4.

From Figure 4(a), it can be concluded that the drought count presented remarkable variations in space, that is, high in NE, C, and N (except the central area), whilst low in NW and southern China (including YR, SW, and SE). Some small regions, such as the region around Shanghai in YR and the coastal area of Fujian province in SE, also have more drought events than around them. Figure 4(b) shows the spatial variation of mean duration. It is long in NW and southern China, while short in C and extremely short in NE. Figure 4(c) shows severe severity in SE and extreme severity in NW, YR, and SW. The mean severity is slight in NE. SPEI is a normalized index. Therefore, the probability of SPEI less than -0.5 should be identical for all stations. The count of drought months can be calculated as drought probability multiplied by the total months. Therefore, the drought months are the same for all sites theoretically. Meanwhile, all drought months also can be calculated based on the multiplication between drought count and mean duration. Therefore, it can be calculated that there is a negative relationship between drought count and average drought duration.

It can be seen that there are many differences between eight regions. In NE, it is prone to have drought with short duration and slight severity. Drought prevention and management of this area should focus on moderate and slight drought. $\mathrm{N}$ and $\mathrm{C}$ are serious area in China, with superior drought frequency, short duration, and moderate severity. The drought prevention ability should be strengthened to reduce the impact on crops in both two regions. In southern China, mean duration is almost 3 months in most stations, much longer than other regions, while severity is extreme. Due to the monsoon, subtropical anticyclone would control southern China with little precipitation and high temperature for a long time, resulting in summer drought. More attention 


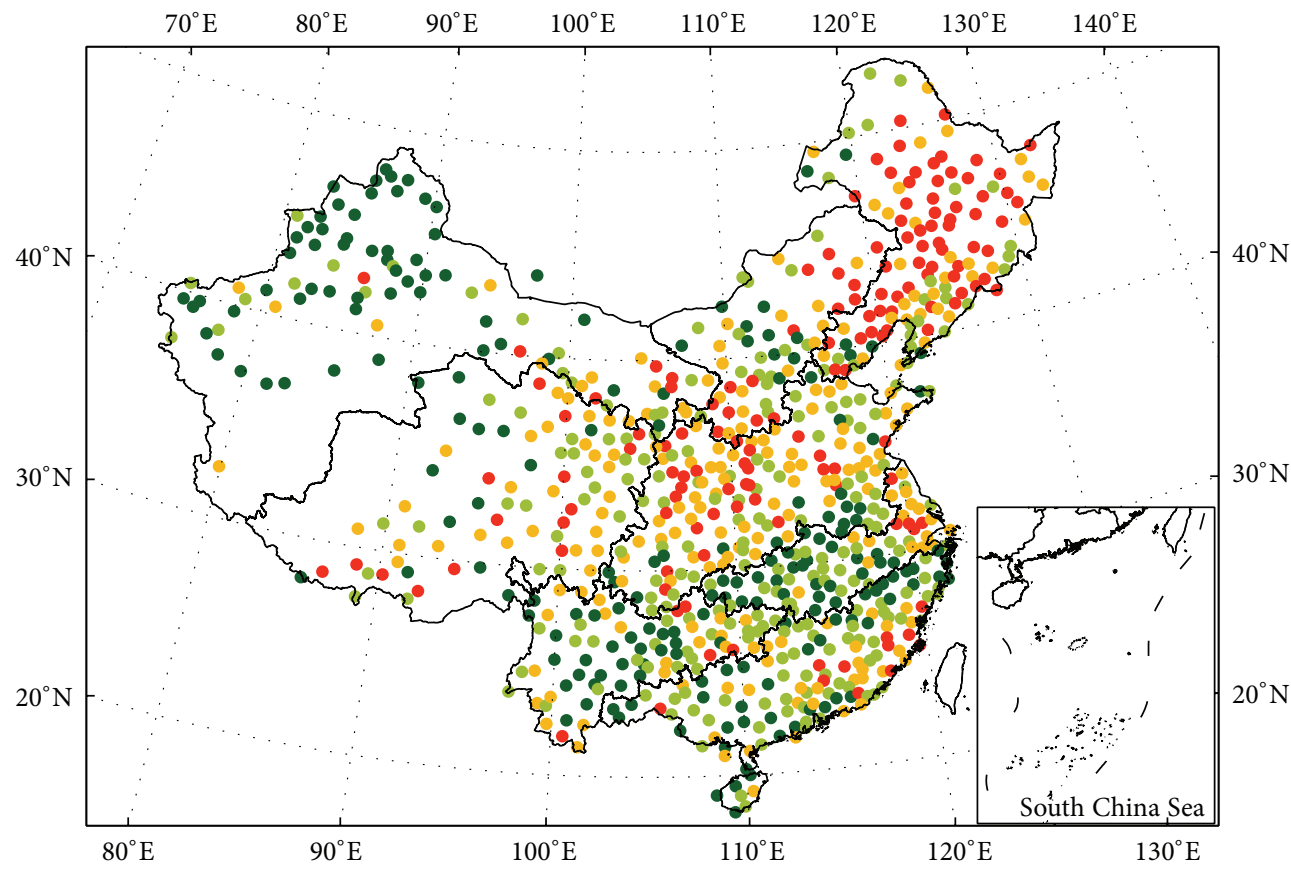

Drought count (number of times)

- Extremely low $(<75)$

- Low (75-80)

- High (80-85)

- Extremely high (>85)

(a)

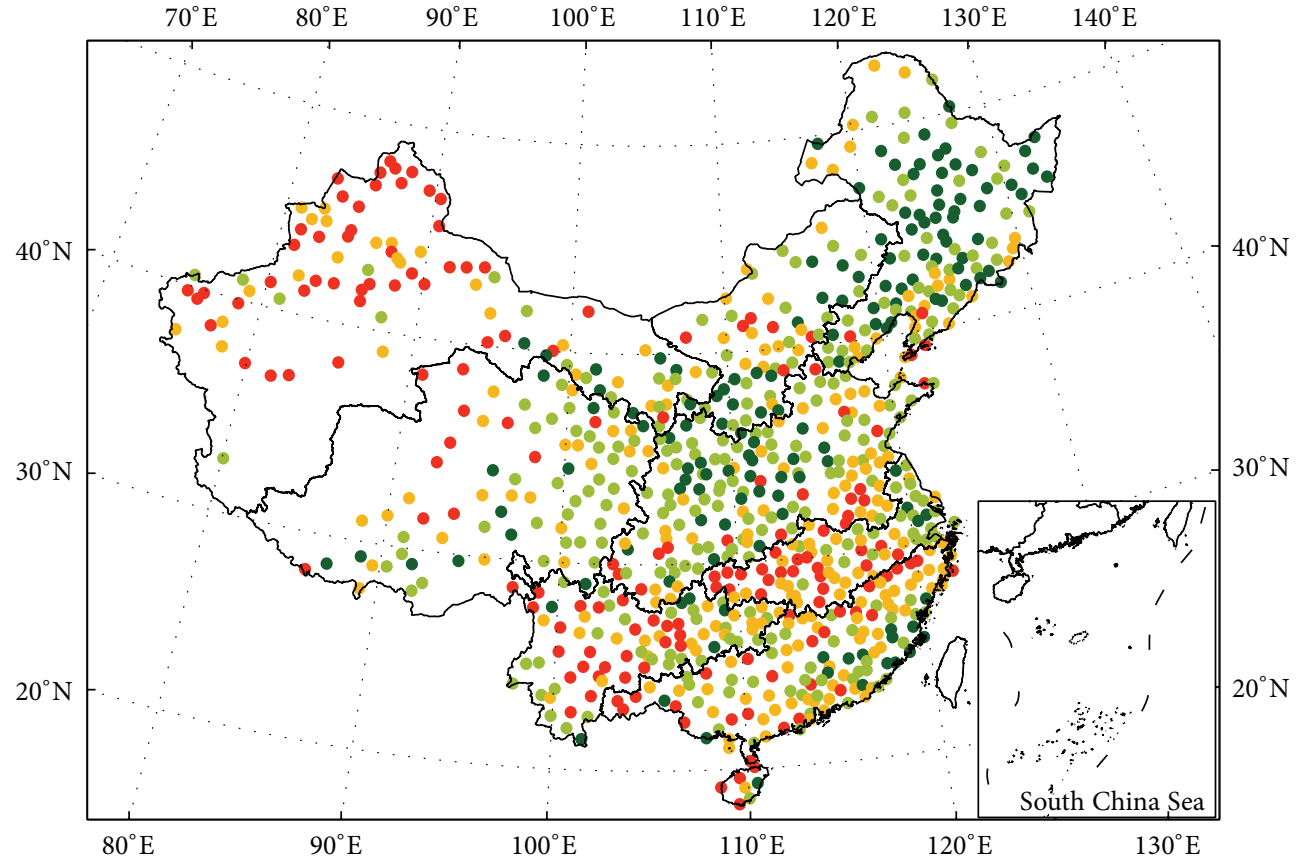

Mean duration (month)

- Extremely short $(<2.4)$

- Short (2.4-2.6)

Long (2.6-2.8)

- Extremely long (>2.8)

(b)

Figure 4: Continued. 


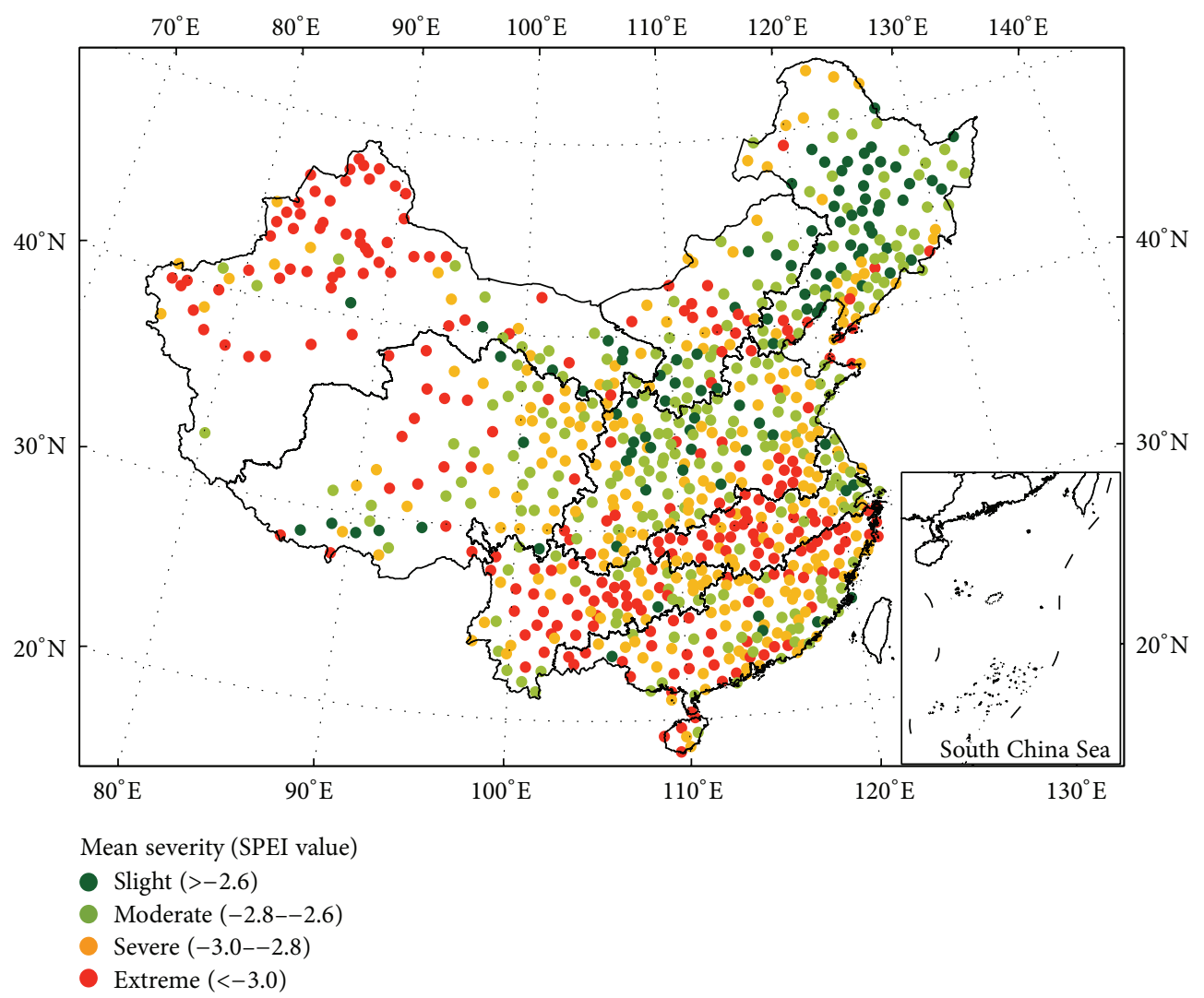

(c)

FIGURE 4: Spatial distribution of drought characteristics over China: (a) drought count; (b) mean duration; (c) mean severity.

must be paid to the severe and extreme droughts in these regions. Several stations (i.e., Chuxiong station and Huaping station) in SW have prolonged duration and extreme severity. These stations locate in climate transition region, and the precipitation change is much larger than around them. The drought that lasted from 2009.9 to 2010.4 affected whole Yunnan province. Chuxiong station has the most dryness among stations in Yunnan. This drought event lasts 13 months with -19.5 severity and -1.93 peak.

4.3. Temporal Variation of Drought Characteristics. Temporal variations of drought characteristics are of great significance for understanding the long-term drought conditions. The temporal variations of drought duration and severity were shown in Figures 5 and 6, respectively. The black line means the average value in this region.

As is shown in Figure 5, there are big differences between eight regions' annual drought duration series. The fluctuation of drought duration is great in SE and YR, while small in TP. Main time-continuous drought events in eight regions are listed: SW (2009 and 2011), NE (2001), N (1998), SE (2003), YR (1978), NW (2006 and 2008), and C (1998). It can be seen that time-continuous droughts mainly took place after 1990 in China. Figure 6 indicates the temporal variation of severity, which is similar with drought duration. Drought events with smaller severity are concentrated in the past 20 years. The long drought duration year is usually accompanied by a low severity. Three temporal drought parameters were all salient in 2009 in SW, demonstrating that extreme drought happened. In general, the three characteristics of drought effectively depict the drought from different aspects. All of them are of great importance to the evaluation of the metrological drought.

The Mann-Kendall trend test was applied to detect the existence of possible trends to severer drought characteristics. The spatial distribution of critical values of $Z$ was presented in Figure 7.

In Figure 7(a), the significant trend towards longer duration (significant at $90 \%, 95 \%, 99 \%$, and $99.9 \%$ confidence intervals, resp.) is mainly found in C and NW. The stations with increasing duration in C mainly locate in Shaanxi, Henan, and northwest part of Hubei province. The stations with increasing duration in NW mainly locate in the southern part. In addition, there are small aggregations in SW (the border between Guizhou, Yunnan, and Sichuan) and NE (near the boundary line of semihumid and semiarid climate). Few stations with that significant trend towards shorter duration are mainly distributed in the northern Xinjiang province and southern TP. In Figure 7(b), it can be seen that the spatial distribution of drought severity tendency is similar to drought duration. But more stations are significant. The SW, NE, N, C, and NW all have a significant trend to 


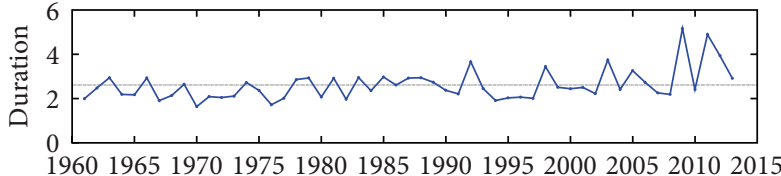

(a)

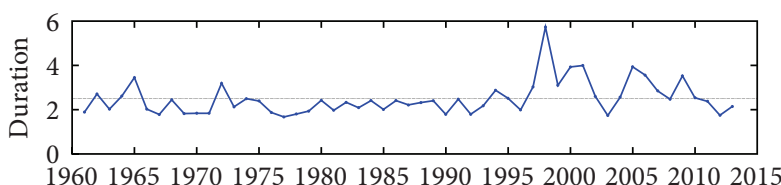

(c)

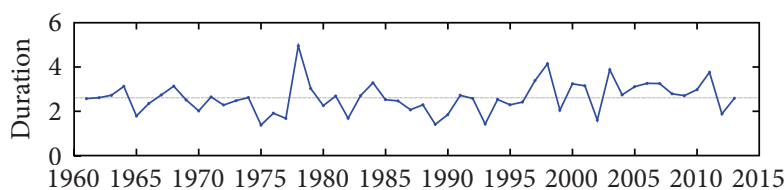

(e)

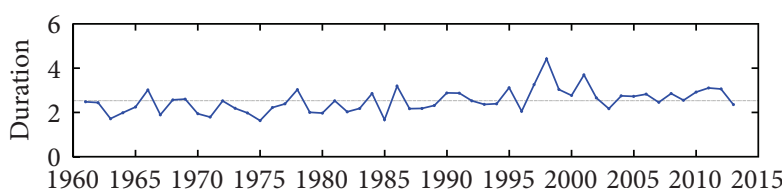

(g)

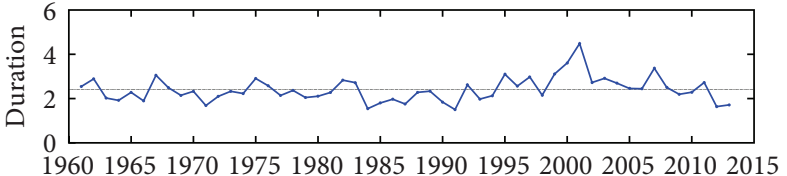

(b)

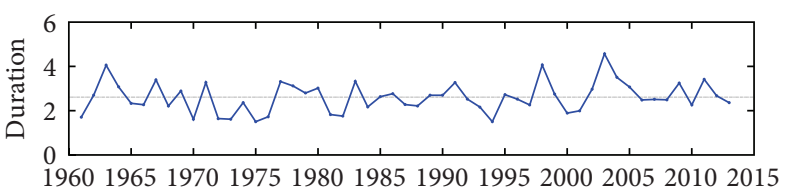

(d)

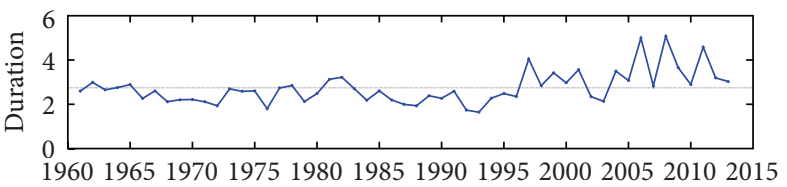

(f)

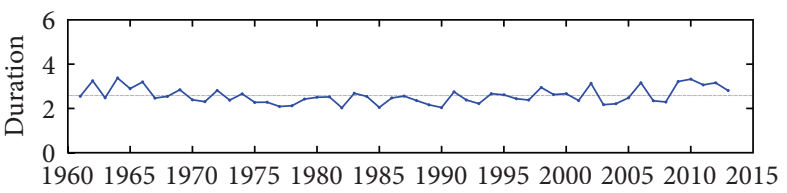

(h)

Figure 5: Temporal variation of drought duration in eight regions: (a) SW; (b) NE; (c) N; (d) SE; (e) YR; (f) NW; (g) C; (h) TP.

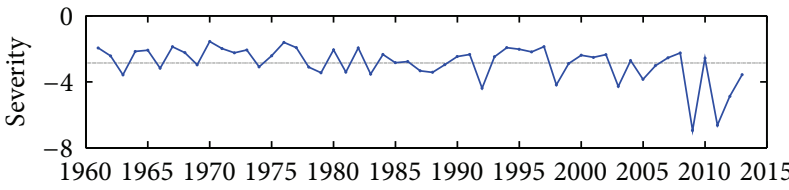

(a)

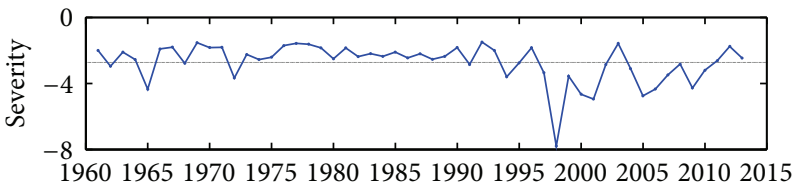

(c)

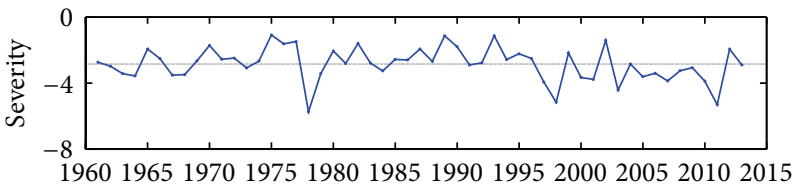

(e)

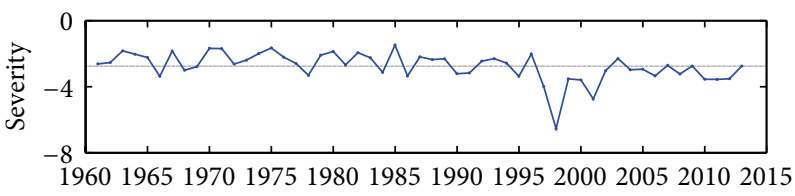

(g)

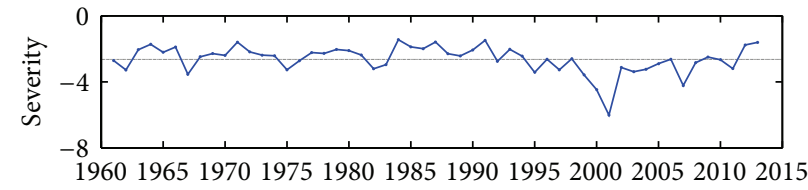

(b)

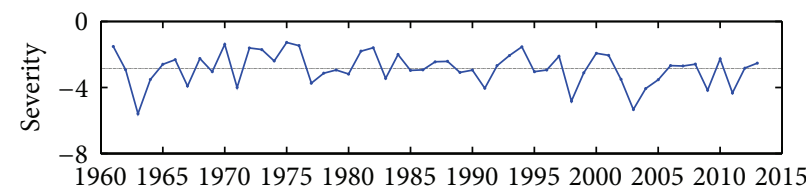

(d)

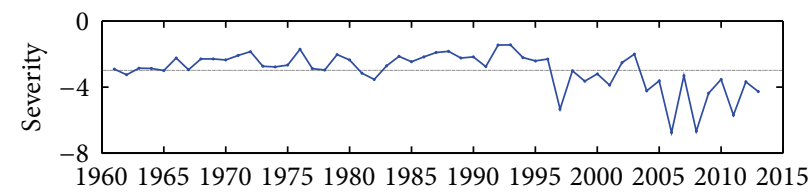

(f)

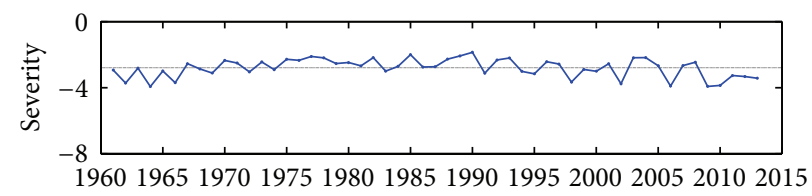

(h)

FIGURE 6: Temporal variation of drought severity in eight regions: (a) SW; (b) NE; (c) N; (d) SE; (e) YR; (f) NW; (g) C; (h) TP. 


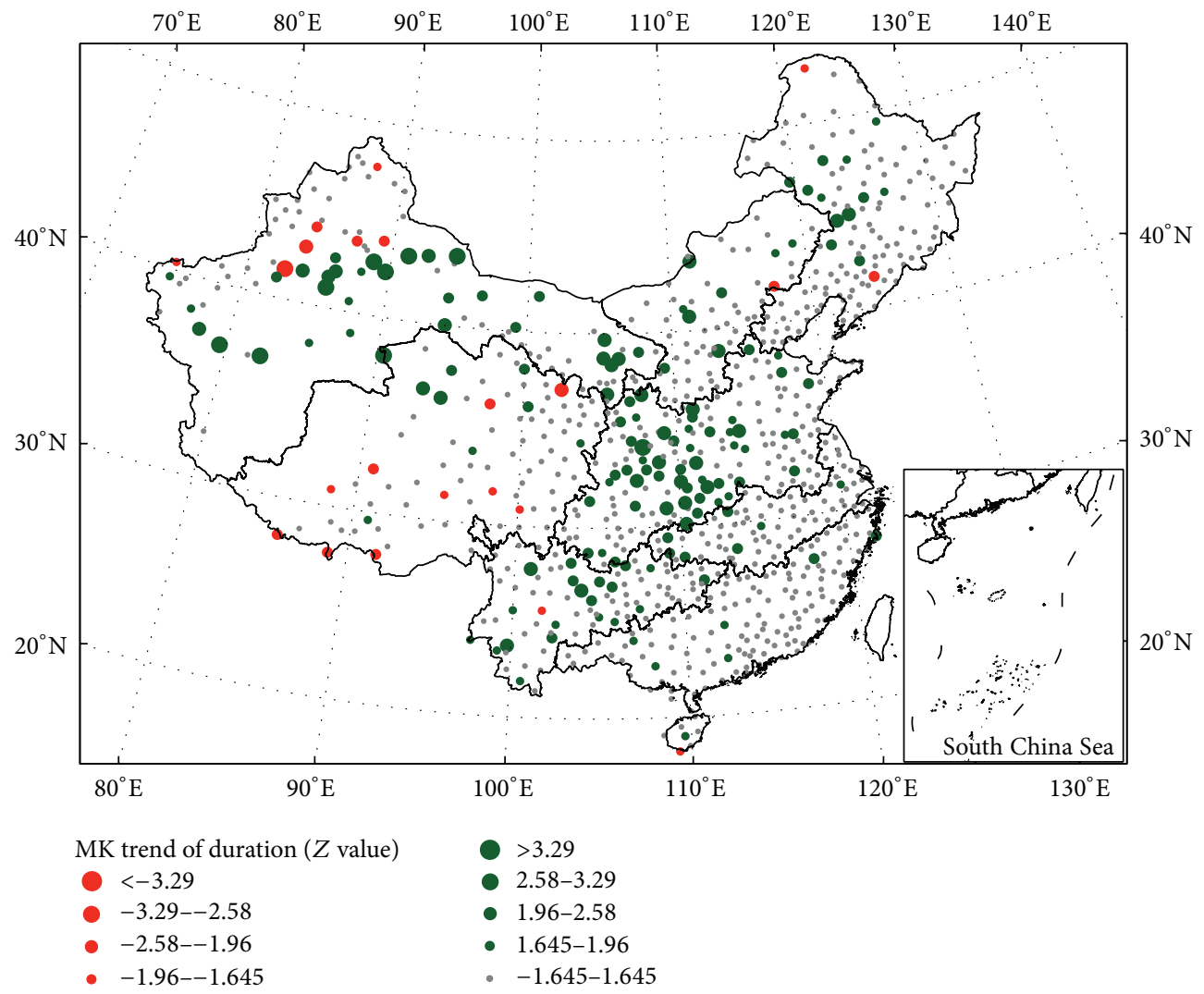

(a)

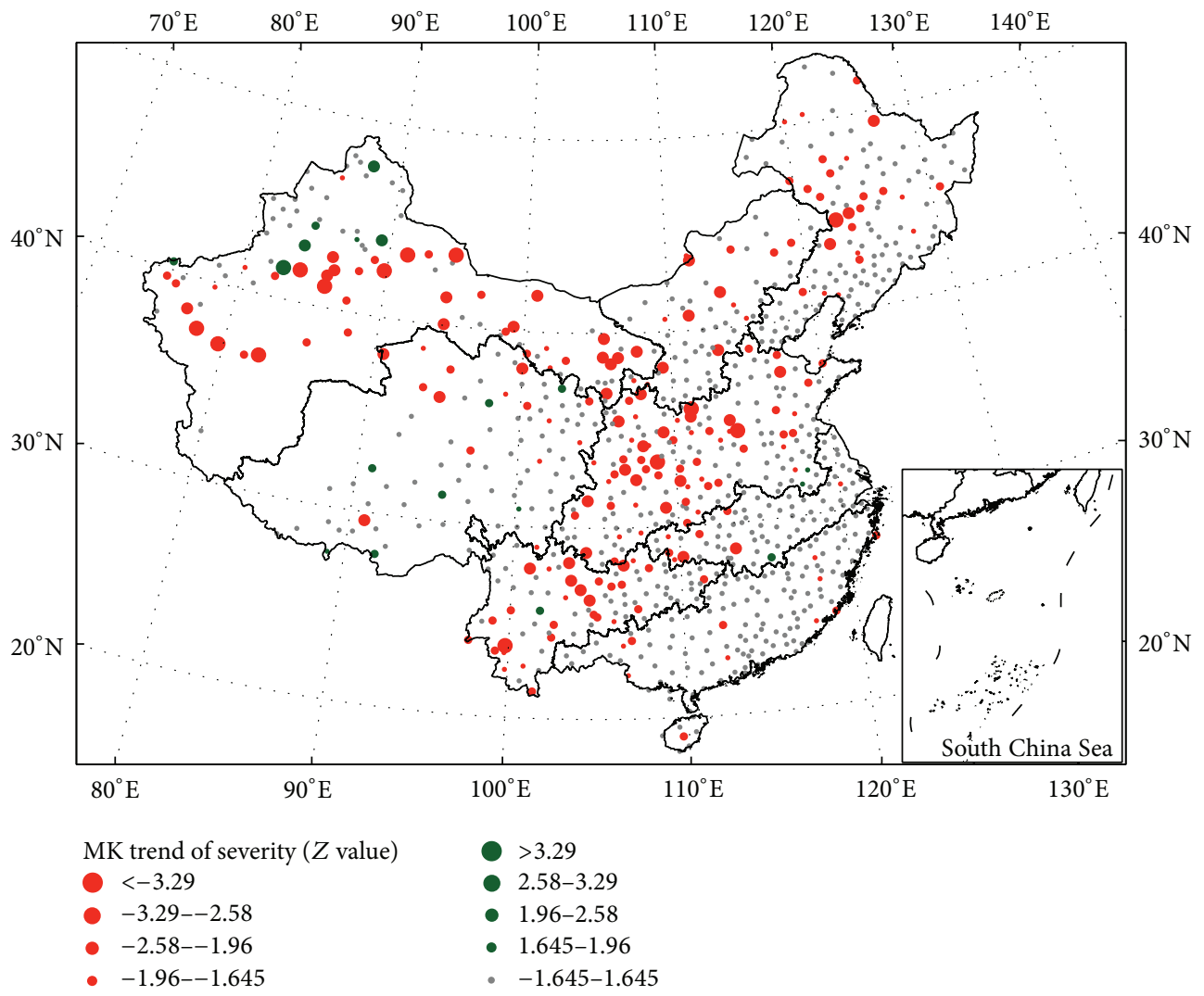

(b)

FIgURE 7: Trend variation of drought characteristics over China: (a) drought duration; (b) drought severity. 
have severer drought characteristics. The ability of drought prevention and management needs to be strengthened in these regions. Shi et al. gave out the trend of precipitation and temperature in China from 1961 to 2010 [46]. By comparing spatial distribution, it can be found that the tendency of drought characteristics shows almost the same significant drying areas with precipitation. This indicated that the drying trend is mainly attributed to the significant reduction in precipitation. However, some precipitation increasing areas, such as north part of TP, also have drought trend for increasing temperature. This result is consistent the recent study by Yu et al. [14].

4.4. Decadal Variation of Severe Drought Frequency. In order to explore the spatiotemporal variation of severe drought frequency over China, the entire study period was subdivided into 6 subperiods: 1961-1969, 1970-1979, 1980-1989, 19901999, 2000-2009, and 2010-2013. Note that 1961-1969 only covers 9 years and 2010-2013 only contains 4 years. However, there are 10 years in other subperiods. Severe drought event was defined as the drought events with peak smaller than -1.5 . Then severe drought frequency can be calculated as the severe drought events count divided by the years count in each subperiod. This would be convenient for the comparison between different decades and help us find decades of high severe drought frequency and the prone drought area in each decade. The result was shown in Figure 8. In view of only 4 years in 2010s, the result cannot represent the spatial distribution of severe drought frequency in the future.

It can be seen that the spatial distributions of severe drought frequency in 6 subperiods are diverse. In 1960s, severe drought would happen 0.58 times per year in YR, which is the most serious region. In addition, SE, the north part of Xinjiang province, and Three Rivers Sources region also have a relatively higher frequency. In 1970s, there was a relatively high frequency in the eastern NE and Hunan province, whilst there was low frequency in $\mathrm{N}$ and $\mathrm{NW}$ with only about 0.20 times per year. In 1980s, high severe drought mainly occurred in the eastern SW, the western SE, and Shandong province. SW is the lowest severe drought risk region. In 1990s, the high severe drought frequency area was mainly distributed in NE, C, and SE. It is much lower in YR, NW, and eastern SW. In 2000s, the severe drought frequency is much higher than before all over China, especially in NE. In 2010s, high severe drought frequency is mainly distributed in SW, C, and southern NW. Besides, it is also very prominent in the coastal area of YR. In these areas, severe drought may happen every year. Taken together, the spatial distribution of high severe drought frequency area is quite different in six decades. In the near future, more attention must be paid to the drought events in C and SW.

It is currently widely accepted that a climate regime shift transpired in the North Pacific Ocean in the winter of 1976-1977 [47-49]. The severe drought frequency also has a corresponding change. The average frequency of all stations over China is 0.30 times per year in 1970s, which is lowest, and rose rapidly to 0.57 times per year in 2000s. For eight regions, the change processes in six subperiods are not the same.
Severe drought frequency of southeast monsoon affected area (including NE, N, C, YR, and SE) reaches the minimum in 1970s or 1980s and then grows rapidly. NE and C have a similar trend, and both increase since 1980s. N and SE have a similar tendency, and both increase since 1970s. In YR, the severe drought frequency decrease from 1960s to 1980s and then starts to increase since 1990s, which is much different from other regions. In SW, there is small growth from 1960s to 1980s and rapid increase in 2000s and 2010s. The highest frequency occurred in 2010s, with the frequency being 0.78 times per year. According to the Bulletin of Flood and Drought Disasters in China, SW is a high incidence area with continuous drought from winter to spring and summer drought within a year. NW and TP show a distinct trend for they are not affected by the East Asian Summer monsoon. In NW, the severe drought frequency is relatively low and stable in the twentieth century and rapidly increases in the twenty-first century. As NW is vast, there is certainly different interior. Northern NW has a declining tendency. On the contrary, the south part is increasing. Drought frequency increases slowly in TP since 1980s.

4.5. Main Factors of Drought. Less precipitation is the main reason of drought, but recent studies also showed that abnormal high temperature also makes an important contribution $[6,14,22,29]$. According to the drought history in recent years [50], serious drought events in China usually come with $30 \%$ precipitation shorter than normal and $80 \%$ lack in extreme condition. Droughts are usually accompanied by high temperature weather in spring and summer, usually $2^{\circ} \mathrm{C}$ higher. Studying how precipitation and temperature affect the SPEI in eight regions in different months can provide effective support for drought monitoring.

The average precipitation and temperature of all stations in one region were used as the data series in this region. Then, the temporal evolution of the 3-month SPEI, PRE, and TEM for all regions was shown in Figure 9, where PRE is the ratio of real monthly precipitation and average monthly precipitation, while TEM is the difference between actual mean monthly temperature and average temperature. From Figure 9, extreme drought events (such as, 1978 drought in YR, 1998 drought in N, 2003 drought in SE, 1998 drought in C, and 2009 drought in SW) can be identified easily. By comparing the SPEI, precipitation, and temperature, it can be found that severe droughts are usually accompanied by reduced precipitation and abnormal high temperature.

In order to demonstrate how precipitation and temperature affect SPEI in different regions in different months, the average data and the adjusted data (15\% precipitation change and $2^{\circ} \mathrm{C}$ temperature change) were added to the data series of each region. Finally, the corresponding SPEI was calculated. The result was shown in Figure 10.

As SPEI is a normalized index, the SPEI of monthly mean precipitation and temperature is close to zero. It can be seen that abnormal precipitation and temperature have significant influence on SPEI in eight regions. Therefore, it is quite necessary to consider the temperature in drought 


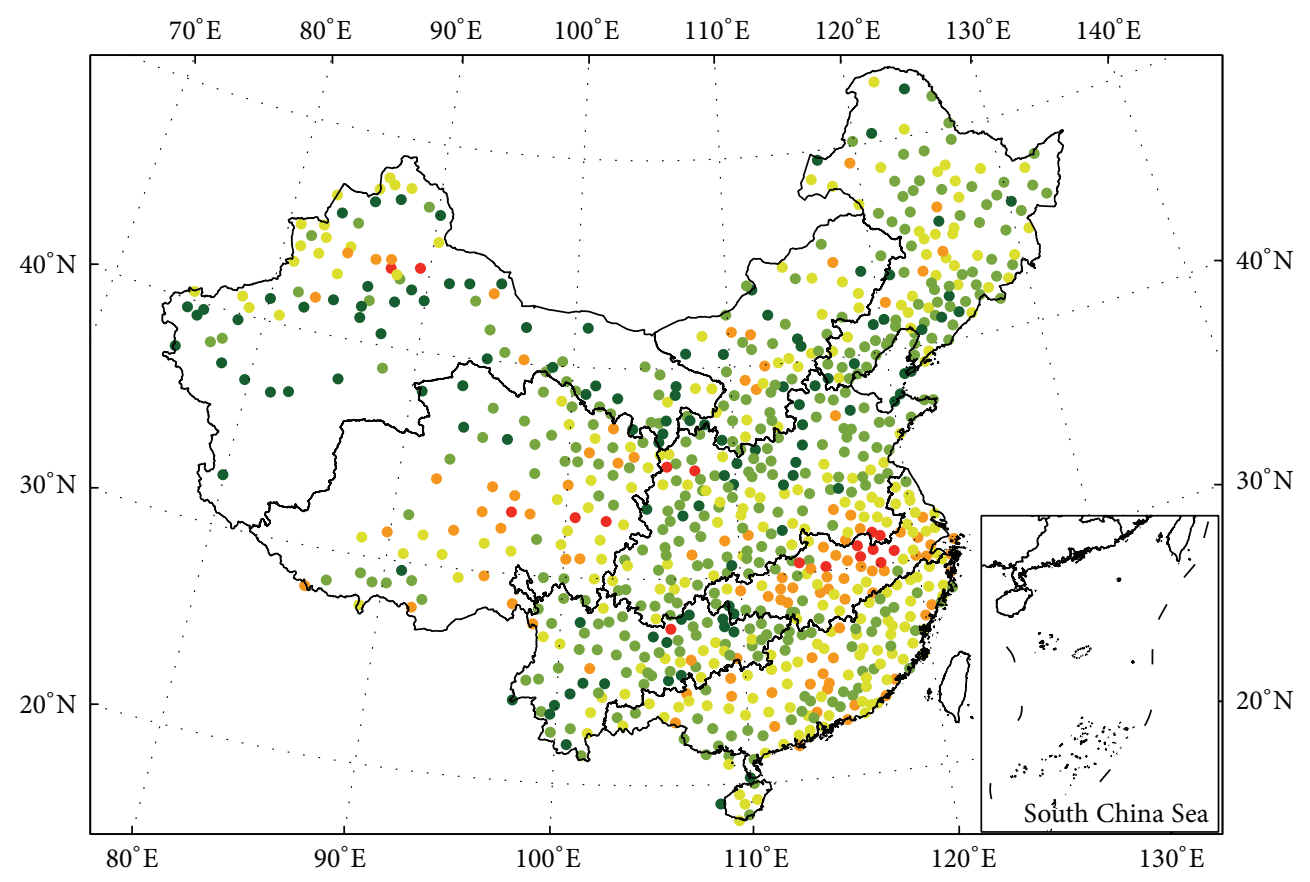

Severe drought frequency (1960s) (times per year)

- $<0.2$

- $0.2-0.4$

$0.4-0.6$
$0.6-0.8$

- $>0.8$

(a)

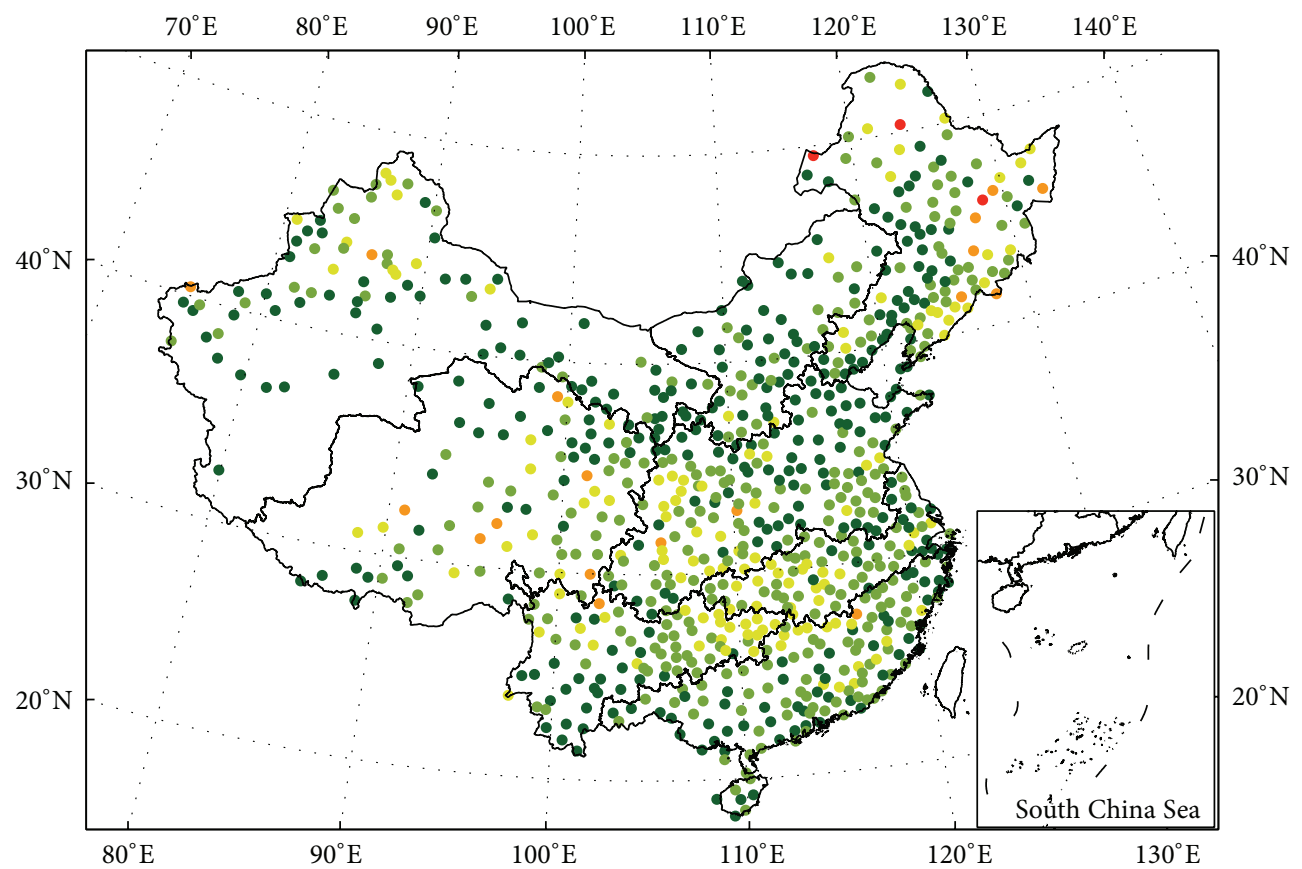

Severe drought frequency (1970s) (times per year)
- $<0.2$
- $0.6-0.8$
- $0.2-0.4$
- $>0.8$
0.4-0.6

(b)

FIgure 8: Continued. 


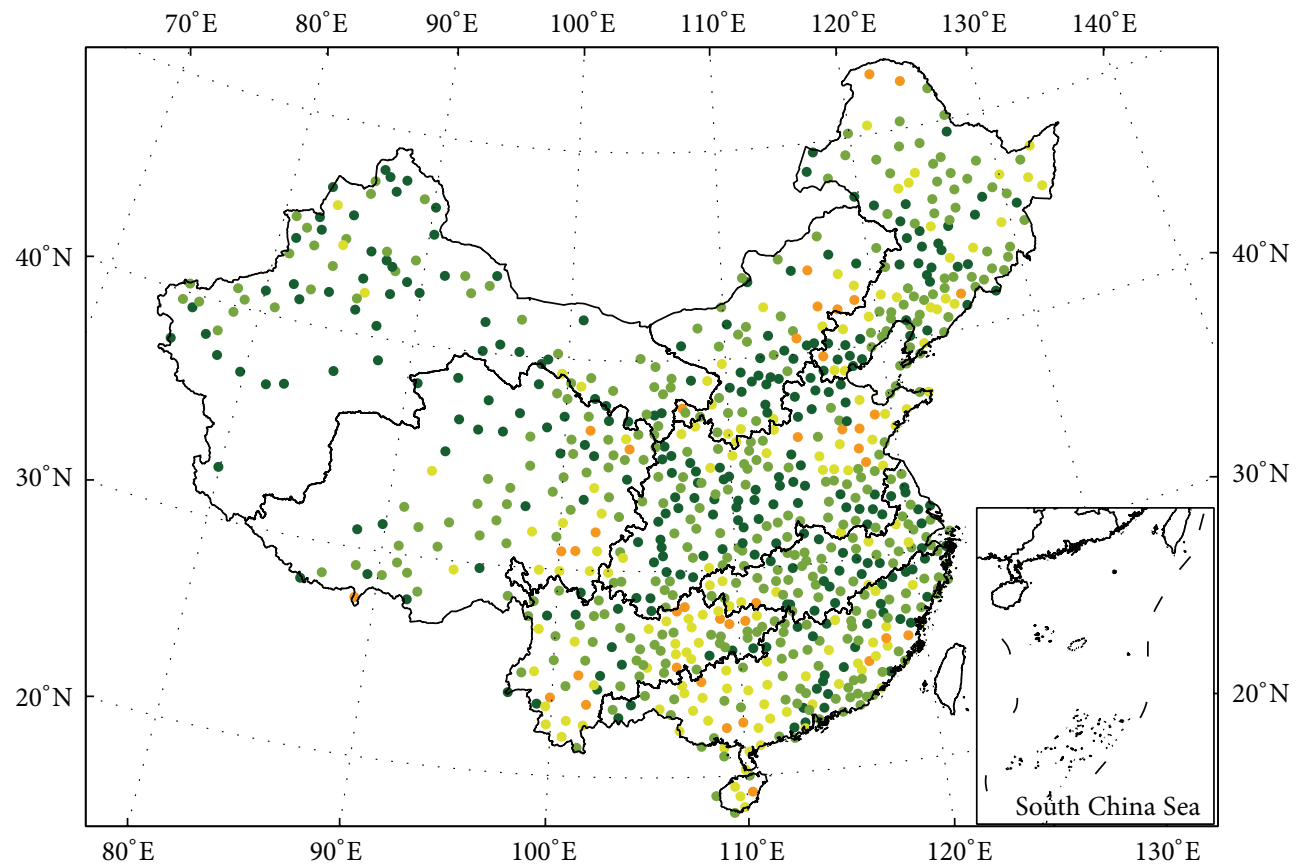

Severe drought frequency (1980s) (times per year)

- $<0.2$

- $0.2-0.4$

$0.4-0.6$
$0.6-0.8$

- $>0.8$

(c)

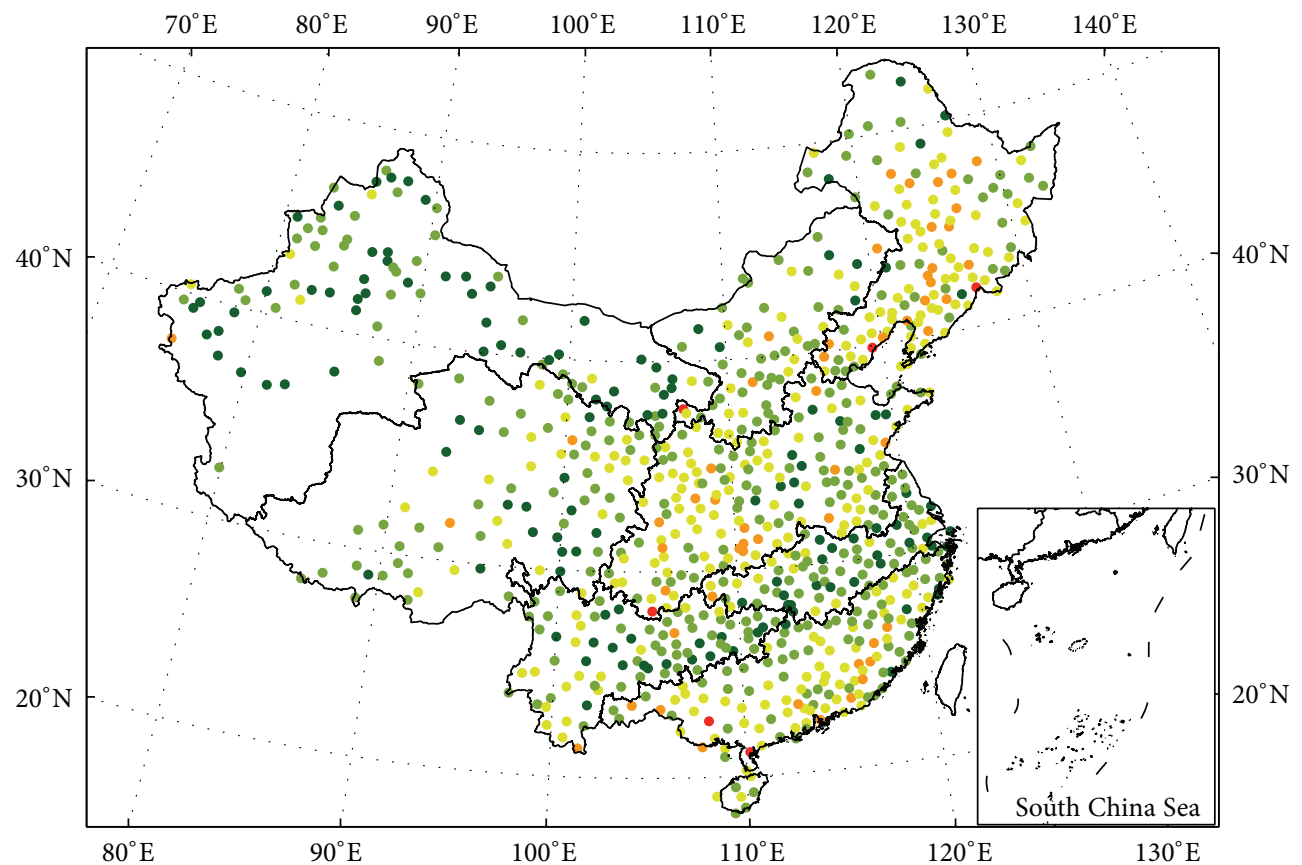

Severe drought frequency (1990s) (times per year)
- $<0.2$
- $0.6-0.8$
$0.2-0.4$
- $>0.8$
$0.4-0.6$

(d)

FIgure 8: Continued. 


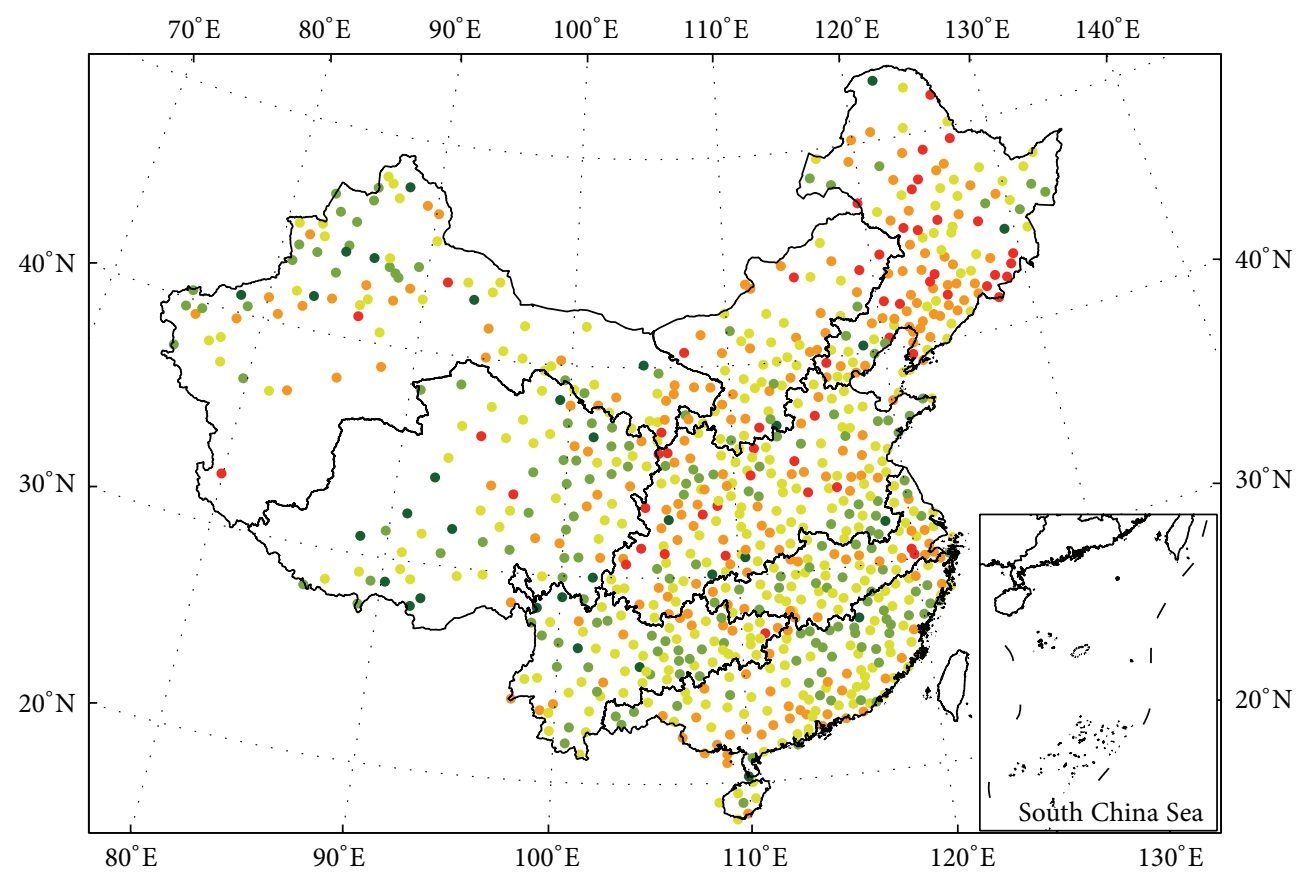

Severe drought frequency (2000s) (times per year)

- $<0.2$

- $0.2-0.4$

$0.4-0.6$
$0.6-0.8$

- $>0.8$

(e)

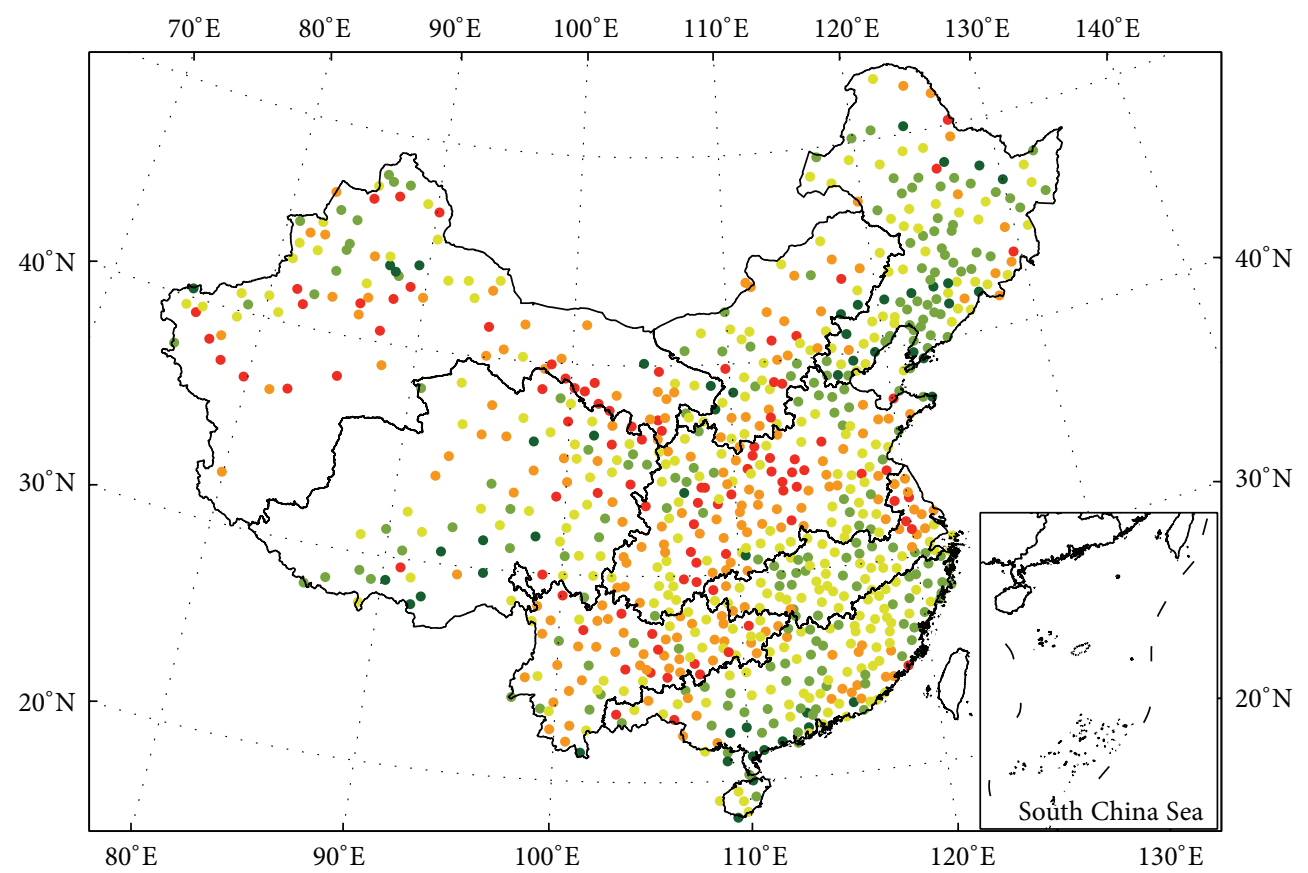

Severe drought frequency (2010s) (times per year)
- $<0.2$
- $0.6-0.8$
- $0.2-0.4$
$>0.8$
0.4-0.6

(f)

Figure 8: Decadal variation of severe drought frequency over China: (a) 1960s; (b) 1970s; (c) 1980s; (d) 1990s; (e) 2000s; (f) 2010s. 


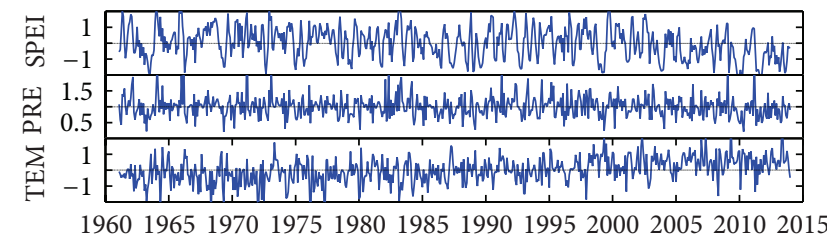

(a)

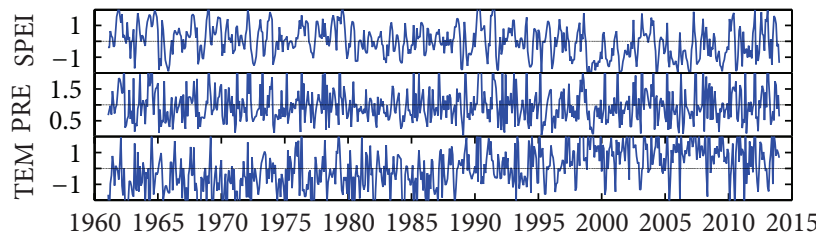

(c)

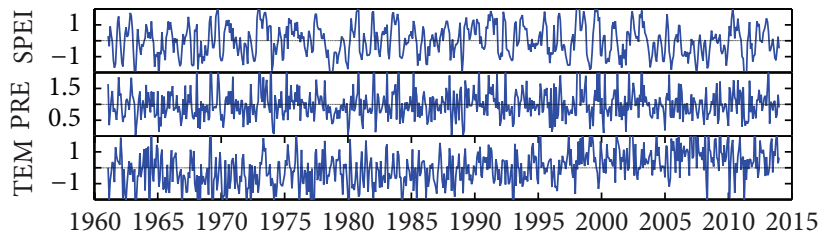

(e)

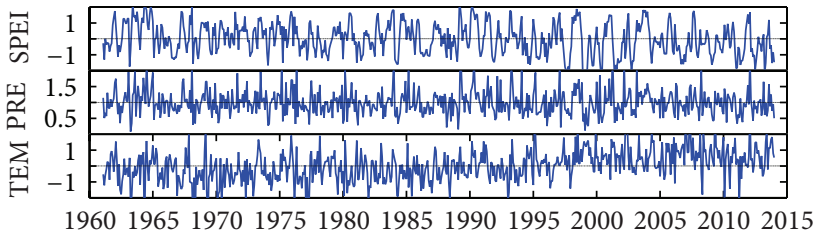

(g)

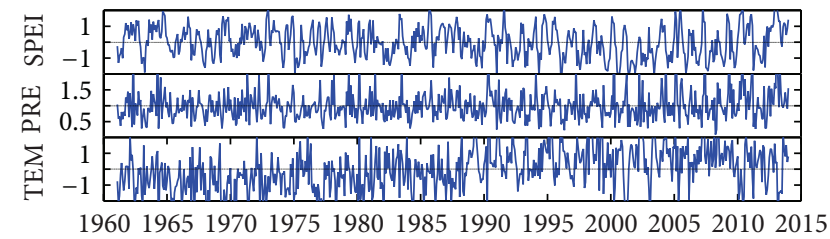

(b)

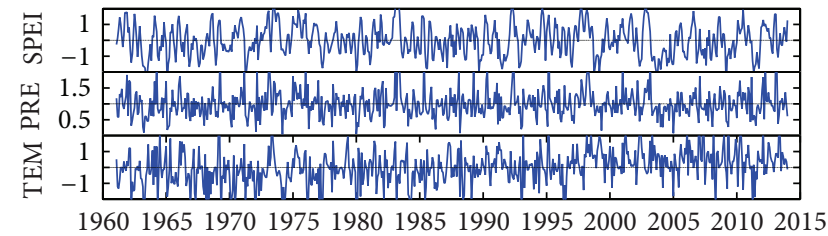

(d)

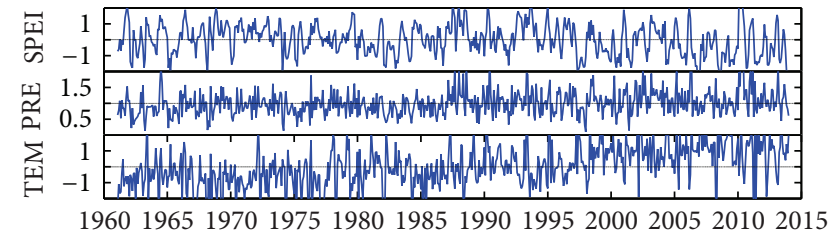

(f)

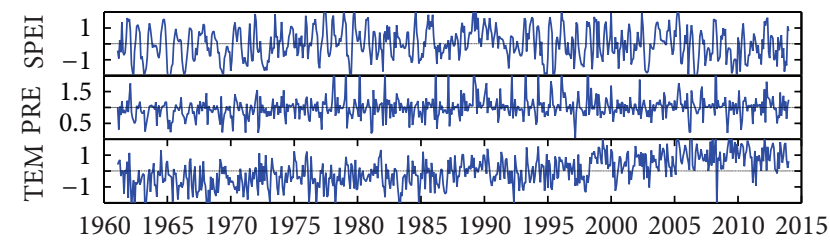

(h)

FIgUre 9: Temporal evolution of the 3-month SPEI in eight regions: (a) SW; (b) NE; (c) N; (d) SE; (e) YR; (f) NW; (g) C; (h) TP.

analysis, especially for applications involving future climate scenarios. Due to the different climate, all regions have different responses to abnormal climate scenarios. In SW, the impact of abnormal precipitation is particularly significant in summer, leading to about 1.5 SPEI change. The effect is much smaller in other seasons, especially in winter with about 0.5 SPEI change. The effect of temperature anomaly is much higher in spring. $2^{\circ} \mathrm{C}$ temperature increases usually lead to 1 SPEI change, leading to moderate drought. The influence of abnormal scenarios is very similar between $\mathrm{C}, \mathrm{NE}$, and $\mathrm{N}$. The impact of abnormal temperature is high in spring, whilst the impact of abnormal precipitation is much bigger in summer than other seasons. The influence of abnormal temperature is more obvious in $\mathrm{N}$ and could lead to 1.5 SPEI changes in spring. It is needed to pay attention; as the monthly mean temperature is lower than 0 degrees in $\mathrm{NE}$ and $\mathrm{N}$ in winter, the evapotranspiration would always set to 0 according to the Thornthwaite formula, leading to no change in SPEI from January to March. This situation also exists in the NW and TP. It concentrated from January to April in TP, a month longer than NE, N, and NW. More attentions should be paid to the abnormal high temperature in spring in these regions.
SE and YR are very similar. The influence of temperature is stable throughout the year with 0.5 SPEI change. The effect of abnormal precipitation is much higher in summer in both regions. SE is more sensitive to the anomalous precipitation. SW and TP both are sensitive to abnormal high temperature. In NW, the temperature change will lead to SPEI change from May to December, which means extreme drought. The influence of precipitation is small in NW, which is because the water is mainly from meltwater instead of rainfall. TP is sensitive to abnormal precipitation from June to November.

\section{Conclusion}

In this paper, drought events in China were investigated based on 810 SPEI series, which covers the period of 1961-2013. Drought regionalization in China was analyzed by applying SKATER to the 3-month SPEI. Then the spatiotemporal patterns of drought characteristics, which are extracted by runs theory, were analyzed over China. Furthermore, how abnormal less precipitation and abnormal high temperature affect SPEI in eight regions was explored. From the results 


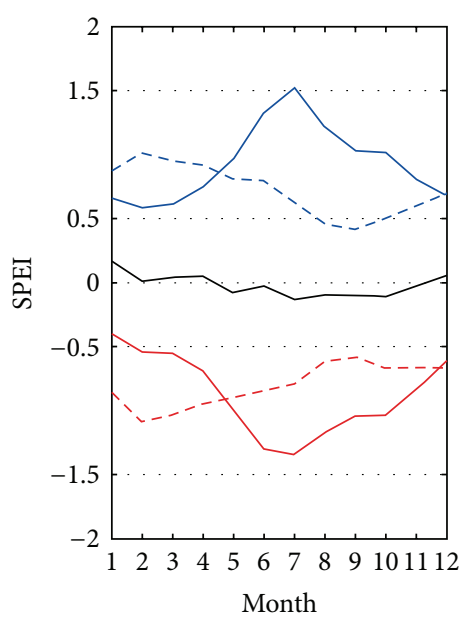

(a)

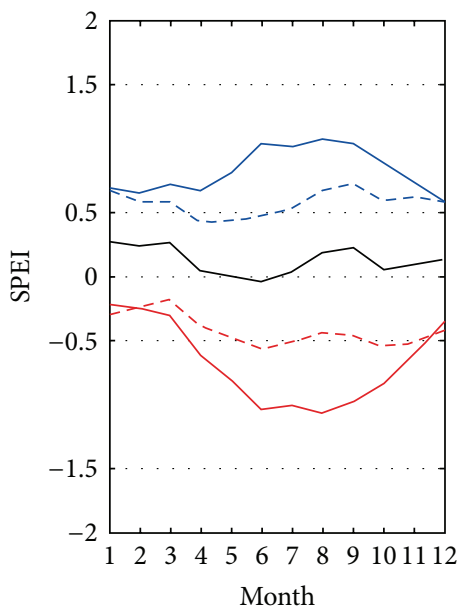

(d)

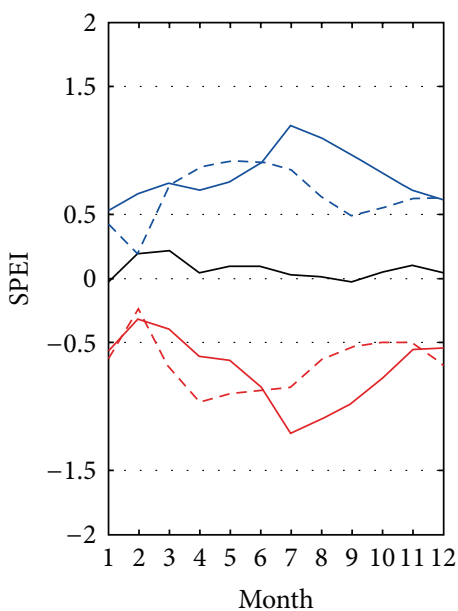

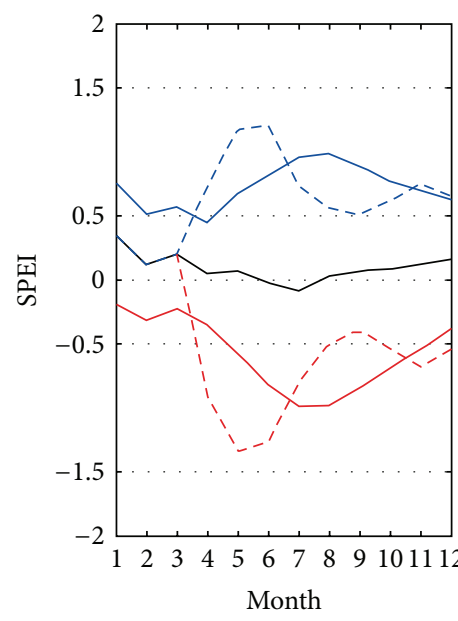

(b)

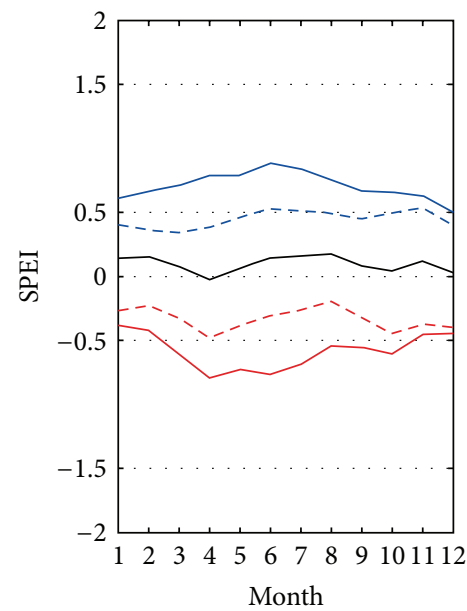

(e)

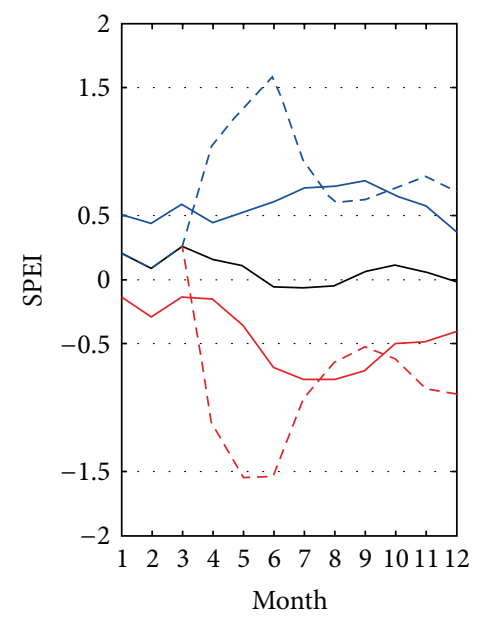

(c)

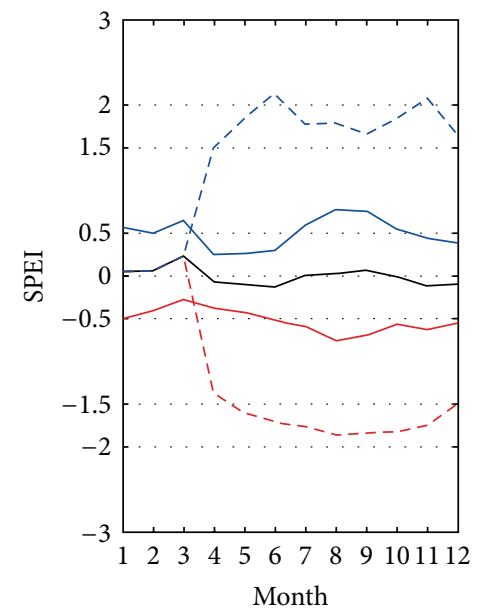

(f)

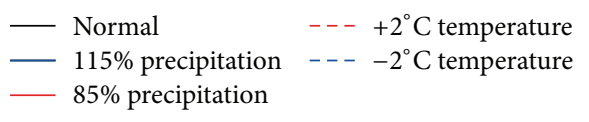

(g)
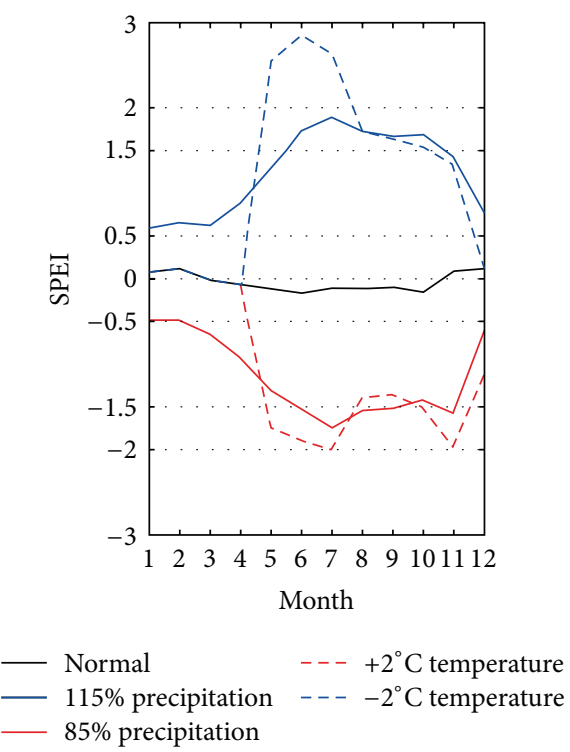

(h)

FIGURE 10: Evolution of the SPEI in eight regions under five scenarios: (a) SW; (b) NE; (c) N; (d) SE; (e) YR; (f) NW; (g) C; (h) TP. 
presented in this study, some conclusions are obtained as follows:

(1) SKATER can get drought regionalization effectively considering both the geographical location and attribute information. China mainland was divided into eight homogeneous subregions: SW, NE, N, SE, YR, NW, C, and TP.

(2) Drought may happen about 80 times in every station from 1961 to 2013. Drought count is significantly high in NE, C, and N (except the central area). Drought duration and severity are significantly high in SW, SE, YR, and NW. However, there are some anomalous zones showing different characteristics with the large region, such as northern Xinjiang province and the coastal area of Fujian province in SE.

(3) Severe droughts mainly occurred after 1990. The drought duration and severity both have a significant increase trend in SW, NE, N, NW, and C.

(4) Severe drought frequency increased since the 1980s and rose rapidly to 0.570 times per year in 2000 s. This growth trend is obvious in the eastern China. The severe drought prone region is YR in 1960s, NE, SE, and C in 1990s, and NE, N, NW and C in 2000s. Severe drought occurrences have become much more frequent in SW, NW, C, and the coastal area of YR in the first four years of 2010s.

(5) Less precipitation and higher temperature are both main factors of drought in China. Influence ability of two factors varies within a year. Briefly, in SW, NE, N, and $\mathrm{C}$, precipitation has bigger influence in summer, and temperature has bigger influence in spring. The main factor of drought is precipitation in SE and YR, whilst it is temperature in NW. The influence of precipitation and temperature are both significant in TP.

These conclusions can provide a scientific basis for the management of drought mitigation strategies. Identifying the drought prone area and period can help decision makers have more information on resource planning. This also will help in environmental protection and agricultural production. However, few limitations remain in the current study. There is still a certain difference between eight regions, so a level two regionalization is very necessary. Drought characteristics were analyses separately, which cannot reveal the drought event.

\section{Conflict of Interests}

The authors declare that there is no conflict of interests regarding the publication of this paper.

\section{Acknowledgments}

The authors wish to thank the editor. The data was obtained from China Meteorological Data Sharing Service System. This work was financially supported by the National Natural
Science Foundation of China (Grant nos. 41301501, 41201441, and 41371363) and Youth Innovation Promotion Association of CAS (2013002).

\section{References}

[1] IPCC, Summary for Policymakers, Cambridge University Press, Cambridge, UK, 2012.

[2] X. J. Liu, J. Q. Zhang, D. L. Ma, Y. L. Bao, Z. J. Tong, and X. P. Liu, "Dynamic risk assessment of drought disaster for maize based on integrating multi-sources data in the region of the northwest of Liaoning Province, China," Natural Hazards, vol. 65, no. 3, pp. 1393-1409, 2013.

[3] Y. P. Qu, J. Q. Li, J. Lyu, Z. C. Su, B. Qiu, and A. H. Li, "A quantitative framework for assessing drought disaster risk and key techniques," Advances in Water Science, vol. 25, no. 2, pp. 297-304, 2014.

[4] E. Lu, Y. L. Luo, R. H. Zhang, Q. Wu, and L. Liu, "Regional atmospheric anomalies responsible for the 2009-2010 severe drought in China," Journal of Geophysical Research D: Atmospheres, vol. 116, no. 21, Article ID D21114, 2011.

[5] A. Mishra and V. Desai, "Spatial and temporal drought analysis in the Kansabati river basin, India," International Journal of River Basin Management, vol. 3, no. 1, pp. 31-41, 2005.

[6] Q. F. Wang, J. J. Wu, T. J. Lei et al., “Temporal-spatial characteristics of severe drought events and their impact on agriculture on a global scale," Quaternary International, vol. 349, pp. 10-21, 2014.

[7] S. M. Vicente-Serrano, "Differences in spatial patterns of drought on different time scales: an analysis of the Iberian Peninsula," Water Resources Management, vol. 20, no. 1, pp. 3760, 2006.

[8] S. M. Vicente-Serrano, "Spatial and temporal analysis of droughts in the Iberian Peninsula (1910-2000)," Hydrological Sciences Journal, vol. 51, no. 1, pp. 83-97, 2006.

[9] K. E. Logan, N. A. Brunsell, A. R. Jones, and J. J. Feddema, "Assessing spatiotemporal variability of drought in the U.S. central plains," Journal of Arid Environments, vol. 74, no. 2, pp. 247-255, 2010.

[10] M. Gocic and S. Trajkovic, "Spatiotemporal characteristics of drought in Serbia," Journal of Hydrology, vol. 510, pp. 110-123, 2014.

[11] M. J. Zhang, J. Y. He, B. L. Wang et al., "Extreme drought changes in Southwest China from 1960 to 2009," Journal of Geographical Sciences, vol. 23, no. 1, pp. 3-16, 2013.

[12] Q. Zhang, M. Z. Xiao, V. P. Singh, and J. F. Li, "Regionalization and spatial changing properties of droughts across the Pearl River basin, China," Journal of Hydrology, vol. 472-473, pp. 355366, 2012.

[13] X. Y. Yu, X. Y. He, H. H. Zheng et al., "Spatial and temporal analysis of drought risk during the crop-growing season over northeast China," Natural Hazards, vol. 71, no. 1, pp. 275-289, 2014.

[14] M. X. Yu, Q. F. Li, M. J. Hayes, M. D. Svoboda, and R. R. Heim, "Are droughts becoming more frequent or severe in China based on the standardized precipitation evapotranspiration index: 1951-2010?" International Journal of Climatology, vol. 34, no. 3, pp. 545-558, 2014.

[15] X. Zou, P. Zhai, and Q. Zhang, "Variations in droughts over China: 1951-2003," Geophysical Research Letters, vol. 32, no. 4, 2005. 
[16] Z. Y. Wang, Y. H. Ding, J. H. He, and J. Yu, "An updating analysis of the climate change in China in recent 50 years," Acta Meteorologica Sinica, vol. 62, no. 2, pp. 228-236, 2004.

[17] Z. H. Jiang and Y. G. Ding, "Regional features of interannual variation of rainfall over China over the past 4 decades," Journal of Nanjing Institute of Meteorology, vol. 17, no. 1, pp. 73-78, 1994.

[18] X. Yang and D. L. Li, "Precipitation variation characteristics and arid climate division in China," Arid Meteorology, vol. 26, no. 2, pp. 17-24, 2008.

[19] L. J. Chen, D. L. Chen, H. J. Wang, and J. H. Yan, "Regionalization of precipitation regimes in China," Atmospheric and Oceanic Science Letters, vol. 2, no. 5, pp. 301-307, 2009.

[20] P. M. Zhai and X. K. Zou, "Changes in temperautre and precipitation and their impacts on drought in China during 1951-2003," Advances in Climate Change Research, vol. 1, no. 1, pp. 16-18, 2005.

[21] P. M. Zhai and X. H. Pan, "Change in extreme temperature and precipitation over northern China during the second half of the 20th century," Acta Geographica Sinica, vol. 58, no. S1, pp. 1-10, 2003.

[22] Y. J. Li, F. M. Ren, Y. P. Li, P. L. Wang, and H. M. Yan, "Characteristics of the regional meteorological drought events in Southwest China during 1960-2010," Journal of Meteorological Research, vol. 28, no. 3, pp. 381-392, 2014.

[23] Q. Zhang, C.-Y. Xu, and Z. Zhang, “Observed changes of drought/wetness episodes in the Pearl River basin, China, using the standardized precipitation index and aridity index," Theoretical and Applied Climatology, vol. 98, no. 1-2, pp. 89-99, 2009.

[24] X. L. Wang, X. Y. Hou, Z. Li, and Y. D. Wang, "Spatial and temporal characteristics of meteorological drought in Shandong Province, China, from 1961 to 2008," Advances in Meteorology, vol. 2014, Article ID 873593, 11 pages, 2014.

[25] W. C. Palmer, Meteorological Drought, US Department of Commerce, 1965.

[26] T. B. McKee, N. J. Doesken, and J. Kleist, "The relationship of drought frequency and duration to time scales," in Proceedings of the 8th Conference on Applied Climatology, pp. 179-183, Anaheim, Calif, USA, January 1993.

[27] Q. Zhang, X. K. Zou, and F. J. Xiao, Classification of Meteorological Drought (GB/T20481-2006), Standards Press of China, Beijing, China, 2006.

[28] G. van der Schrier, J. Barichivich, K. R. Briffa, and P. D. Jones, "A scPDSI-based global data set of dry and wet spells for 19012009," Journal of Geophysical Research: Atmospheres, vol. 118, no. 10, pp. 4025-4048, 2013.

[29] S. M. Vicente-Serrano, S. Beguería, and J. I. López-Moreno, "A multiscalar drought index sensitive to global warming: the standardized precipitation evapotranspiration index," Journal of Climate, vol. 23, no. 7, pp. 1696-1718, 2010.

[30] S. M. Vicente-Serrano, S. Beguería, J. I. López-Moreno, M. Angulo, and A. El Kenawy, "A new global $0.5^{\circ}$ gridded dataset (1901-2006) of a multiscalar drought index: comparison with current drought index datasets based on the palmer drought severity index," Journal of Hydrometeorology, vol. 11, no. 4, pp. 1033-1043, 2010.

[31] J. Lorenzo-Lacruz, S. M. Vicente-Serrano, J. I. López-Moreno, S. Beguería, J. M. García-Ruiz, and J. M. Cuadrat, "The impact of droughts and water management on various hydrological systems in the headwaters of the Tagus River (central Spain)," Journal of Hydrology, vol. 386, no. 1-4, pp. 13-26, 2010.
[32] C. Shi and X. D. Liu, "Continent drought characteristics over the Eastern Hemisphere from 1947 to 2006-analyses based on the SPEI dataset," Journal of Desert Research, vol. 32, no. 6, pp. 1691-1701, 2012.

[33] Q. X. Li, W. J. Dong, W. Li et al., "Assessment of the uncertainties in temperature change in China during the last century," Chinese Science Bulletin, vol. 55, no. 19, pp. 1974-1982, 2010.

[34] P. M. Atkinson and C. D. Lloyd, "Mapping precipitation in Switzerland with ordinary and indicator kriging," Journal of Geographic Information and Decision Analysis, vol. 2, no. 1-2, pp. 72-86, 1998.

[35] A. K. Mishra and V. P. Singh, "A review of drought concepts," Journal of Hydrology, vol. 391, no. 1-2, pp. 202-216, 2010.

[36] C. W. Thornthwaite, "An approach toward a rational classification of climate," Geographical Review, vol. 38, no. 1, pp. 55-94, 1948.

[37] T. Yang, Q. X. Shao, Z.-C. Hao et al., "Regional frequency analysis and spatio-temporal pattern characterization of rainfall extremes in the Pearl River Basin, China," Journal of Hydrology, vol. 380, no. 3-4, pp. 386-405, 2010.

[38] R. Modarres and A. Sarhadi, "Statistically-based regionalization of rainfall climates of Iran," Global and Planetary Change, vol. 75, no. 1, pp. 67-75, 2011.

[39] D. Guo, "Regionalization with dynamically constrained agglomerative clustering and partitioning (REDCAP)," International Journal of Geographical Information Science, vol. 22, no. 7, pp. 801-823, 2008.

[40] J. Mennis and D. Guo, "Spatial data mining and geographic knowledge discovery-an introduction," Computers, Environment and Urban Systems, vol. 33, no. 6, pp. 403-408, 2009.

[41] R. M. Assunção, M. C. Neves, G. Câmara, and C. Da Costa Freitas, "Efficient regionalization techniques for socio-economic geographical units using minimum spanning trees," International Journal of Geographical Information Science, vol. 20, no. 7, pp. 797-811, 2006.

[42] V. Yevjevich and J. Ingenieur, An Objective Approach to Definitions and Investigations of Continental Hydrologic Droughts, Colorado State University, Fort Collins, Colo, USA, 1967.

[43] H. B. Mann, "Nonparametric tests against trend," Econometrica, vol. 13, no. 3, pp. 245-259, 1945.

[44] M. G. Kendall, Rank Correlation Methods, Griffin, Oxford, UK, 1948.

[45] T. Salmi, Detecting Trends of Annual Values of Atmospheric Pollutants by the Mann-Kendall Test and Sen's Slope Estimates: The Excel Template Application MAKESENS, Ilmatieteen Laitos, 2002.

[46] P. J. Shi, S. Sun, M. Wang et al., "Climate change regionalization in China (1961-2010)," Science China Earth Sciences, vol. 57, no. 11, pp. 2676-2689, 2014.

[47] N. E. Graham, "Decadal-scale climate variability in the tropical and North Pacific during the 1970s and 1980s: observations and model results," Climate Dynamics, vol. 10, no. 3, pp. 135-162, 1994.

[48] C. C. Ebbesmeyer, D. R. Cayan, D. R. McLain, F. H. Nichols, D. H. Peterson, and K. T. Redmond, "1976 step in the Pacific climate: forty environmental changes between 19681975 and 1977-1984," in Proceedings of the 7th Annual Pacific Climate Workshop, pp. 115-126, California Department of Water Resources, Asilomar, Calif, USA, 1991. 
[49] A. Miller, D. Cayan, T. Barnett, N. Graham, and J. Oberhuber, "The 1976-77 climate shift of the pacific ocean," Oceanography, vol. 7, no. 1, pp. 21-26, 1994.

[50] State Flood Control and Drought Relief Office and The Ministry of Water Resources of the People's Republic of China, Bulletin of Flood and Drought Disasters in China, China Water Power Press, 2006-2013. 

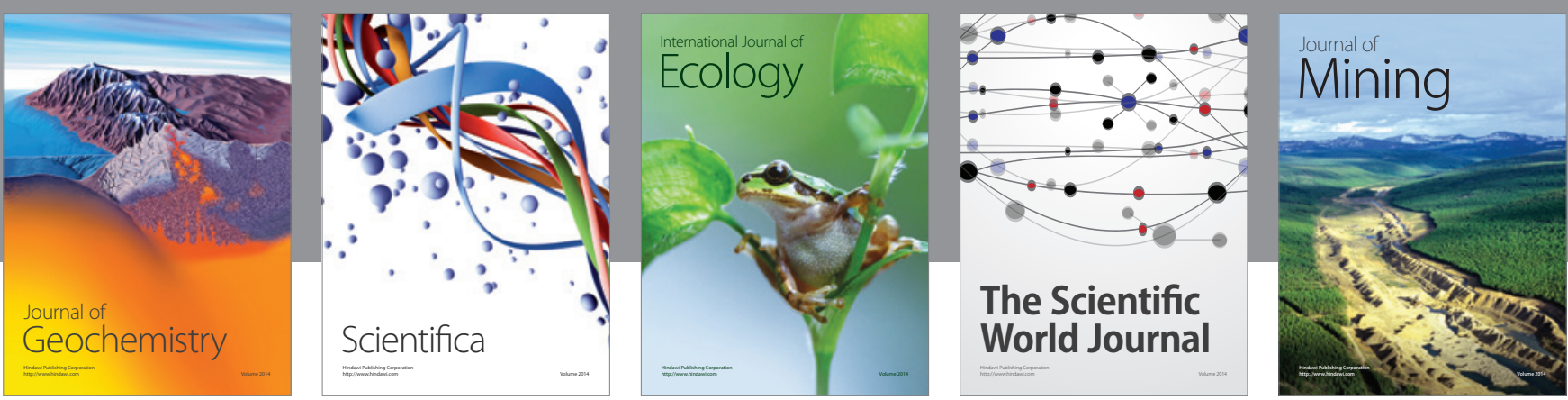

The Scientific World Journal
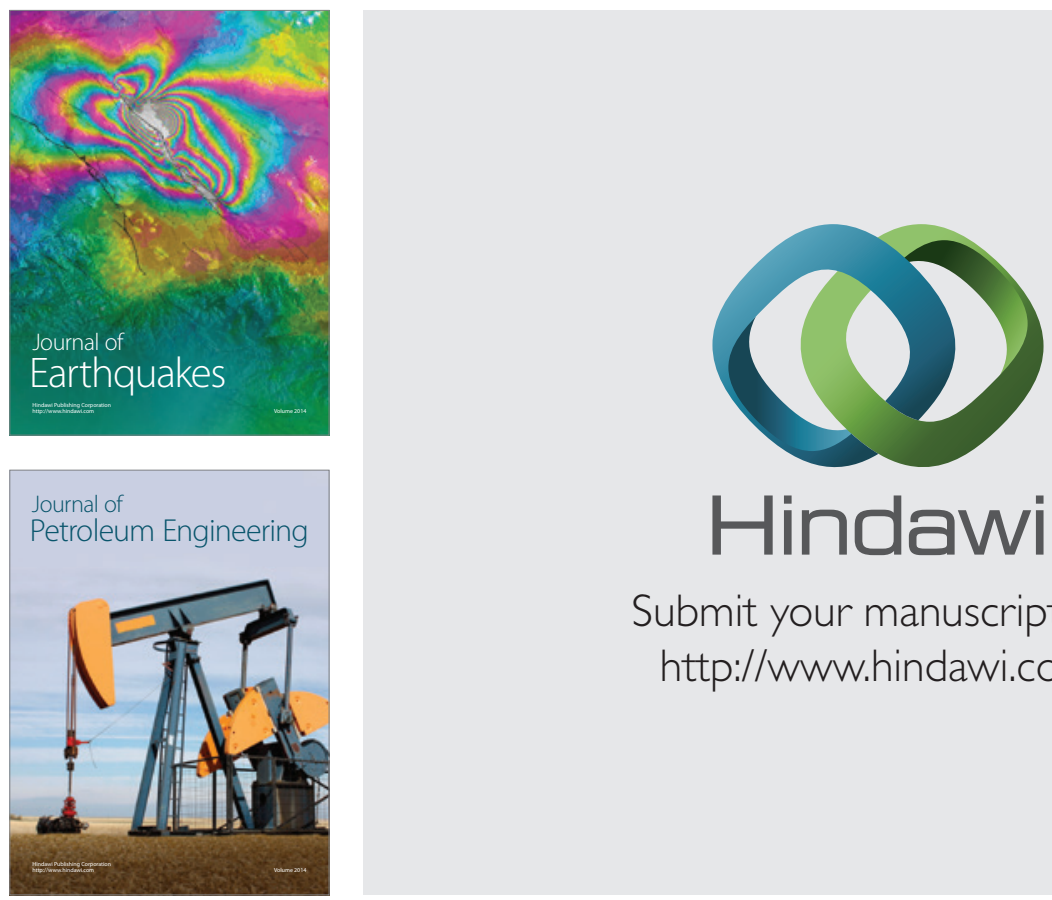

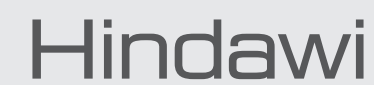

Submit your manuscripts at

http://www.hindawi.com
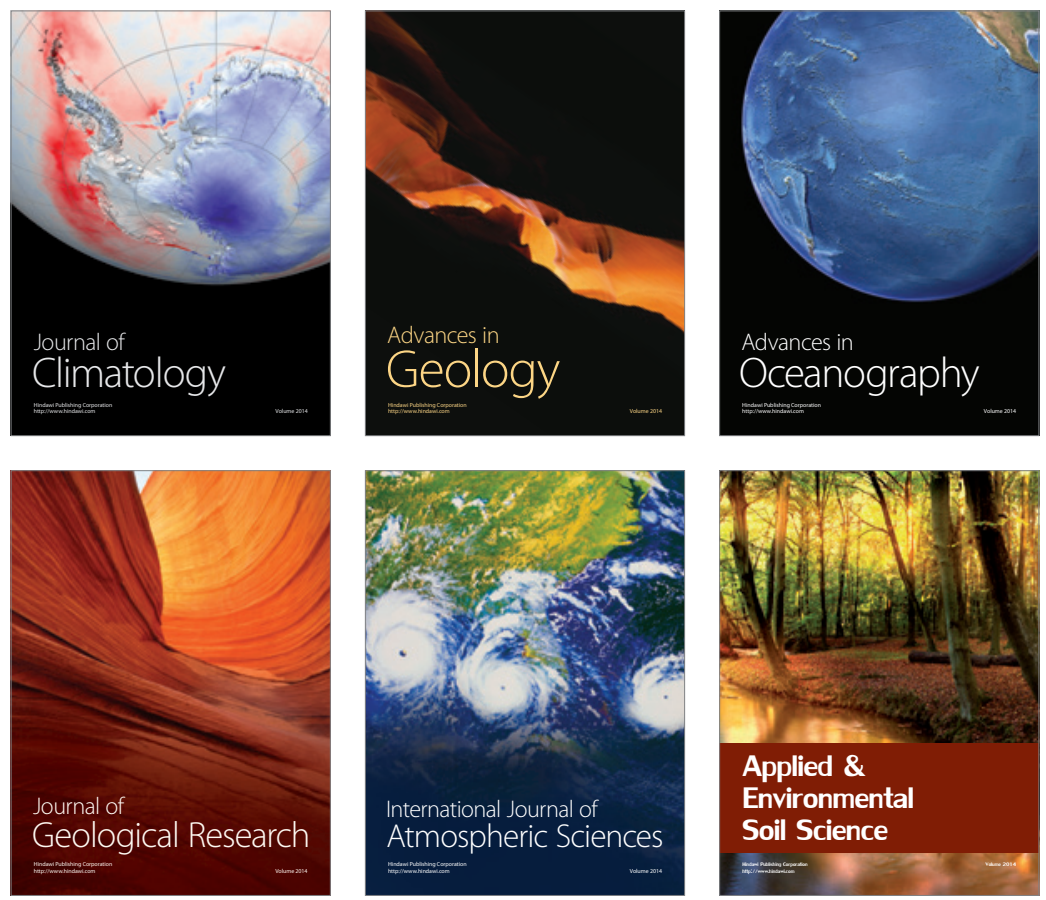
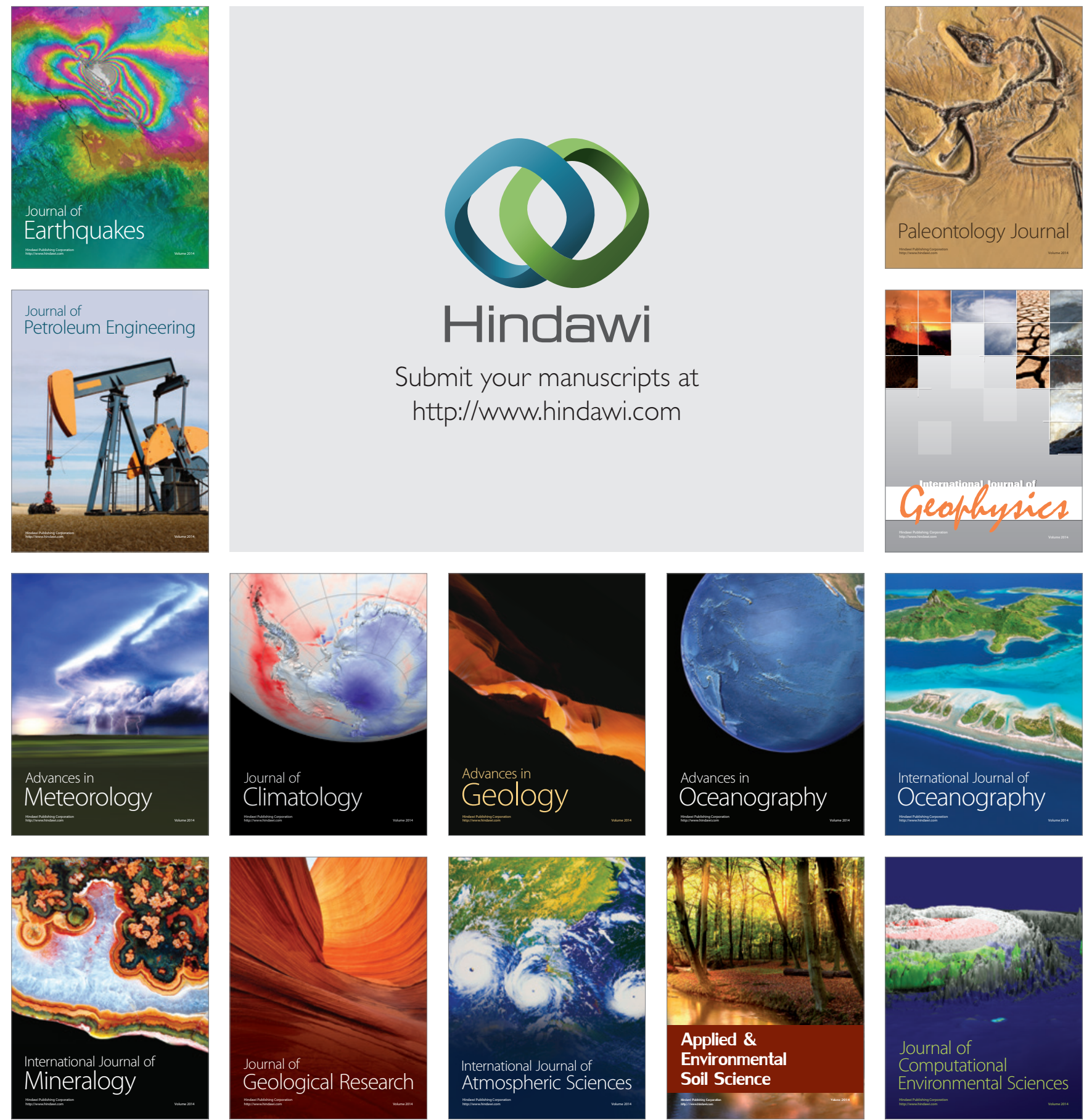